\title{
Modeling and simultaneous management of electric vehicle penetration and demand response to improve distribution network performance
}

Alireza Bakhshinejad ( $\sim$ alireza.bakhshinejad@gmail.com )

Islamic Azad University of Lahijan https://orcid.org/0000-0002-1659-5315

Abdolreza Tavakoli

Islamic Azad University of Lahijan

Maziar Mirhosseini Moghadam

Islamic Azad University of Lahijan

Original article

Keywords: Cost reduction, Demand response, Distribution network, Electric vehicles, Smart management

Posted Date: March 23rd, 2020

DOI: https://doi.org/10.21203/rs.3.rs-18065/v1

License: (1) (i) This work is licensed under a Creative Commons Attribution 4.0 International License.

Read Full License

Version of Record: A version of this preprint was published at Electrical Engineering on August 10th, 2020. See the published version at https://doi.org/10.1007/s00202-020-01083-7. 


\section{Abstract}

Background: The usage of electric vehicles is daily increasing. It is predicted that the penetration of electric vehicles in the electrical network will grow steadily during the next few years. This growth of penetration causes major challenges for power system users, especially the distribution network. Firstly, increasing load consumption, especially during peak hours, and secondly, increasing the cost of developing a network to provide load, along with the operation moved away from the optimum point, are the major challenges of the penetration of electric vehicles. The aim of this study is to propose a solution not only to resolve these challenges but also to make an opportunity to improve the network parameters.

Methods: The charging and discharging strategy along with two price-based and voltage-based load management programs are proposed to manage the penetration of electric vehicles for economic and technical purposes. The proposed plan is implemented by GAMS and MATLAB software on the distribution network.

Results: The test network used in this study is the 37 buses low voltage network. The voltage of this network is $400 \mathrm{~V}$ and its power reference is $100 \mathrm{kVA}$. The upstream nominal capacity is $800 \mathrm{kVA}$. The allowed voltage range is also $0.9 \mathrm{pu}$ to $1.05 \mathrm{pu}$. The network loads are indoor and equipped with electric vehicle parking.

Conclusions: The results showed that by properly managing the penetration of electric vehicles along with responsive loads, not only were the network parameters not compromised and the penetration of all the vehicles was managed without the need for network development, but also by applying the proposed strategy, the network parameters were improved.

\section{Background}

The automotive industry has led to the advance of the global economy and has provided an easier life for humans. However, many vehicles that use an internal combustion engine cause serious problems including air pollution, global warming, and the rapid drain of oil and gas resources. Governments have therefore begun to reduce their dependence on fossil fuels by increasing the efficiency and usage of clean vehicles [1]. By electric vehicles (EVs), gasoline consumption and air pollution are reduced in metropolitan areas. Hence, in order to reduce energy consumption and help the environmental crises, it is offered to use this kind of vehicles instead of internal combustion vehicles in the transportation sector. Using twoway converters in electric vehicles, the vehicle would have the ability to transfer energy from its battery to the network [2].

An electric network is used to charge the batteries of electric vehicles. An element called the charger exists between the battery and the electric network. The charger consists of two AC/DC and DC/DC converters, which is responsible for converting AC to DC [3]. Electric vehicles are generally connected to the network between 14:00 and 24:00 for charging, and they are in traffic from 5:00 to 10:00 without any connection to the network. According to these hours, the time of charging electric vehicles overlaps with 
the peak power consumption in the network. Therefore, the connection of electric vehicles to the power network without management and coordination leads to a significant increase of the amount of energy demanded by the network during peak hours. This, in addition to causing price jumps during peak hours, will lead to increase in losses, increase in the probability of network instability due to the bus voltage drop more than the permissible limit. It also makes the power of the lines exit from the allowed value. As a result, the lines exit from the circuit [4]. Therefore, the penetration of these vehicles into the power network, especially the distribution network, causes some challenges. Without efficient power management of electric vehicles, power demand increases during peak load times. And consequently, the voltage of all buses decreases and the network losses increase. Hence, network stability becomes an important problem [3]. Neglecting the challenges of high energy demand during peak hours causes the network indices, both in terms of stability and reliability, to tend to an inappropriate situation. In order to resolve these challenges, some researchers have been done and some solutions have been proposed to reduce the problems caused by the usage of the electric vehicles in the distribution network.

In [5], the synchronous charging of electric vehicles is proposed to reduce the variance of distribution system load by considering uncertainty. In [6], the effects of electric vehicle charger connection on the smart network are investigated and a solution is presented to reduce the loss and to improve the voltage characteristic of the charger. Reference [7] discusses the use of distributed generation sources (DGs) in reducing losses and improving voltage profiles in a smart network with charging stations. In order to predict the future of the load charging of electric vehicles in the future of Iranian electricity distribution networks, a probabilistic model is presented in [8]. Reference [9] investigates the effect of the different magnitudes of electric vehicle charging on the distribution network from two aspects of network loss and voltage drop. In [10], given the physical forces applied to a moving vehicle, a method is presented to develop and implement the physical and electrical model of an electric vehicle. The role of distribution transformers in smart networks with synchronous charging of electric vehicles is studied in [11]. Reference [12] studies the integration of PEV and distributed energy sources in electricity distribution systems. Based on a rechargeable electric vehicle, a study on analyzing and modeling the load flow of voltage source converter has been conducted in [13]. Reference [14] investigates the effect of battery charging of electric vehicles on distribution transformers. In [15], the synchronous charging of hybrid electric vehicles is studied to reduce the loss of the distribution network. In order to minimize power loss and improve voltage profile, the straight away synchronization of charging plug-in hybrid vehicles in smart networks is studied in [16]. Reference [17] presents a new method for simultaneous locating and measuring separate charging stations and EVs and also for managing the vehicle charging process. $\operatorname{In}[18]$, A real-time charging scheme has been presented to coordinate the electric vehicle charging at the parking station. This charging planning has been performed as a binary optimization problem. In [19], a model prediction-based control approach is designed to handle the planning of shared charging of PEV and power control to minimize PEV charging costs and power generation costs. Reference [20] proposes a smart charging strategy for the PEV network that offers various charging options.

In the present study, an optimal design will be implemented to manage the presence of electric vehicles in the distribution network. Minimizing the cost of purchasing energy of electric vehicles, the cost of load 
supply, and the cost of power losses from the optimal amount are considered as the objective function of the optimization problem. According to the objective function structure and the constraints of the problem, this plan provides the optimum operation of the distribution network with the presence of electric vehicles. Minimizing the cost of load supply, losses, and purchasing energy of electric vehicles within the 24-hour time horizon is considered as an objective function. According to this objective function, electric vehicles receive power from the network at a time when the electricity price is low, and demand responses are used to reduce costs and losses. In general terms, this study presents the modeling and simultaneous management of electric vehicle power and demand response, which will improve distribution network performance.

\section{Methodology And Results}

In this section, a model is presented to manage the charge and discharge of electric vehicles in the distribution network. In this model, the multi-objective optimization problem is designed to improve the network parameters and also the energy cost management in the distribution network. The objective functions of the problem are designed to simultaneously manage and navigate several basic network parameters.

These objectives are as follows:

1. Reducing the cost of energy supply for consumption loads.

2. Reducing the cost of line losses.

3. Managing exchangeable energy with electric vehicles.

4. Reducing the voltage deviation of the network buses

\section{Proposed optimal operation model}

In the proposed model, for the electric vehicle, the following factors are considered:

1. The exchange and balance of power between vehicle battery and distribution network

2. Technical limitations of electric vehicle charging

3. Energy consumed or stored in electric vehicles

In this model, demand response management, along with electric vehicles, is also proposed to help improve distribution network performance, especially during peak times. This management plan expresses the load behavior against incentives and uses it to improve network operation. Demand loads are modeled in two ways:

1. Cost-sensitive loads

2. Voltage-sensitive loads

The management of electric vehicles is based on the following three assumptions: 
1. Electric vehicles are connected to the network for charging or discharging indoor parking.

2. Electric vehicles return to the parking lot and they are connected to the network after being used during the day.

3. Electric vehicles are connected to the network only once a day, for charging or discharging. In other words, the frequent interconnection of vehicles throughout the day is ignored.

The decision variables considered in the plan of the distribution network management with the penetration of electric vehicles and demand response are:

1. Charging and discharging power of electric vehicles

2. Active and reactive power of demand response

Therefore, exchanging power with the electric vehicle and the load participation rate in the load response program are the two main tools that change the process of operation of the distribution network. The other network variables such as bus voltage, line passing throughput, etc. are dependent variables.

\section{The objective function of the optimization problem}

The four main objectives, in the proposed management plan, are considered as follows:

1. Minimizing the cost of energy supply needed for network load on the planning horizon

2. Minimizing the cost of network losses in the planning horizon

3. Energy management of exchanges between electric vehicles and the upstream network in the planning horizon

4. Minimizing the deviation of the voltage from the nominal value in the planning horizon

The first two objectives are to manage the distribution network economically. The demand response program is used as an efficient tool to reduce the cost of energy supply. The third objective is to manage the penetration of electric vehicles in the distribution network and to minimize the cost of supplying the required energy to the first two objective functions. Finally, the fourth objective function is designed to improve the buses voltage as one of the basic parameters of the network and, as far as possible, to reach their nominal value. The objective function of the proposed model is expressed as follows.

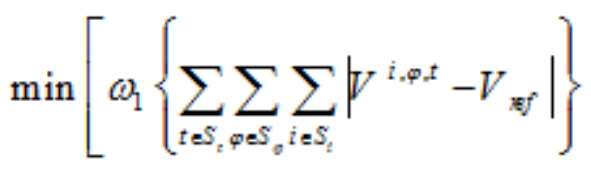

$$
\begin{aligned}
& \left.+\omega_{2}\left\{\sum_{t \in S_{t}} \rho^{t}\left(P_{D R_{-} \text {Tocsi }}^{t}+P_{\text {Loss }}{ }^{t}\right)\right\}+\omega_{3}\left\{\sum_{t \in S_{t}} \sum_{E \in S_{Y}} \rho^{t} P_{E V}^{E, t}\right\}\right]
\end{aligned}
$$


Where, $t$ is the time scheduling stage index, $i$ and $j$ are the bus indexes, $E$ is the electric vehicle index, $\varphi$ is the phase index studied in the three-phase distribution network, $S_{t}$ is the time horizon studied set, $S_{i}$ is the network bus set, $V_{\text {ref }}$ is the magnitude of nominal voltage domain, $\rho$ is the power price, $P_{D R}$ is the active network demand response, $P_{\text {LOSS }}$ is the loss rate of network active power, $P_{E V}$ is the active exchange power with electric vehicle, $V$ is the network voltage, and $\mathrm{P}$ is the active power passing through the line.

The first part of the objective function represents the minimization of the voltage deviation of all buses at all simulation times (planning horizon) and for all the network phases of nominal value. The second part of the objective function addresses the cost of providing active load and the cost of network losses. The price element $\rho$ is considered as a variable at different times. As energy prices change or the voltage of the buses diverges from the nominal value, according to the demand response strategy, some or all of the network loads respond to these changes and change their active and reactive power. It should be noted that the price of losses per kilowatt-hour is equal to the cost of load per kilowatt-hour. The third part of the objective is to model the purchase price of electricity by electric vehicles. $\omega_{1}, \omega_{2}, \omega_{3}$ are the objective function weighting coefficients, which are selected according to the operator's preference for operating the distribution network. The larger weight factor is multiplied into any part of the objective function which has higher priority

\section{Constraints and limitations of the proposed model}

The optimal response will be valid if it observes the network constraints. In other words, due to the limitations of the power transmission in the network and the technical constraints of different equipments, the optimization problem should be solved and the final solution must be extracted.

\section{Power flow constraints}

The equilibrium of produced and consumed power is the most important principle of stability in the power system. At this constraint, at each bus, the summation of inline power, load power, and upstream network injected power must be zero. The active and reactive power which passes from the bus $i$ to the bus $j$ is calculated by the following equation:

$$
\begin{gathered}
P^{i, j}=V^{i} V^{j}\left(G^{i, j} \cos \left(\theta^{i}-\theta^{j}\right)+B^{i, j} \sin \left(\theta^{i}-\theta^{j}\right)\right) \\
Q^{i, j}=V^{i} V^{j}\left(G^{i, j} \sin \left(\theta^{i}-\theta^{j}\right)-B^{i, j} \cos \left(\theta^{i}-\theta^{j}\right)\right)
\end{gathered}
$$


where $G^{i, j}$ are $B^{i, j}$ the rows of the $i$-th and $j$-th columns of the conductance and suspension matrix, respectively, and $\mathrm{Q}$ is the reactive power passing through the line.

According to the above equations, in the proposed model, the summation of the injective power to the bus $i$ from all the lines connected to this bus is calculated by the following equations:

$$
\begin{aligned}
& P^{(i, j), \varphi, t}= \\
& \sum_{j \in S_{s}} V^{i, \varphi, t} V^{j, \varphi, t}\left(G^{i, j} \cos \left(\theta^{i, \varphi, t}-\theta^{j, \varphi, t}\right)+B^{i, j} \sin \left(\theta^{i, \varphi, t}-\theta^{j, \varphi, t}\right)\right) \\
& \forall i \in S_{i}, \varphi \in S_{\varphi, t} \in S_{t} \\
& Q^{(i, j), \varphi, t}= \\
& \sum_{j \in S_{s}} V^{i, \varphi, t} V^{j, \varphi, t}\left(G^{i, j} \sin \left(\theta^{i, \varphi, t}-\theta^{j, \varphi, t}\right)-B^{i, j} \cos \left(\theta^{i, \varphi, t}-\theta^{j, \varphi, t}\right)\right) \\
& \forall i \in S_{i}, \varphi \in S_{\varphi}, t \in S_{t}
\end{aligned}
$$

According to the equilibrium power constraint per bus, we have:

$$
\begin{aligned}
& P^{i, \varphi, t}=P_{G}^{i, \varphi, t}-P_{L}^{i, \varphi, t} \quad \forall i \in S_{i}, \varphi \in S_{\varphi}, t \in S_{t} \\
& Q^{i, \varphi, t}=Q_{G}^{i, \varphi, t}-Q_{L}^{i, \varphi, t} \quad \forall i \in S_{i}, \varphi \in S_{\varphi}, t \in S_{t}
\end{aligned}
$$

In the above equations, the equilibrium of power injected bylines and posts and consumed by the load (electric vehicles and loads) in each bus is evaluated. The power consumed per bus includes the load demanded and the power consumption of the electric vehicle. It should be noted that all network loads participate in the demand response program. $P_{L}$ is the total active power per network bus, $Q_{L}$ is the total reactive power per network bus, $P_{G}$ is injectable power from substation per bus (upstream network injected power), and $Q_{G}$ is reactive power injectable from substation per bus (injectable through Upstream network). 


$$
\begin{aligned}
P_{L}^{i, \varphi, t}= & P_{D R}^{i, \varphi, t}+ \\
& \sum_{E \in S_{z}} A_{1} A_{2} P_{E V}^{i, \varphi, t} \quad \forall i \in S_{i}, \varphi \in S_{\varphi}, t \in S_{t} \\
Q_{L}^{i, \varphi, t}= & Q_{D R}^{i, \varphi, t} \quad \forall i \in S_{i}, \forall \varphi \in S_{\varphi}, t \in S_{t}
\end{aligned}
$$

where $A_{1}$ is the phase confluence matrix of the electric vehicle and ${ }^{A_{2}}$ is the matrix of the confluence of the electric vehicle and bus.

\section{Electric vehicle constraints}

Electric vehicle constraints fall into three categories:

1. Limitation of the interchange power of the vehicle with the network

2. Technical limitation of vehicle battery

3. Energy-related restrictions on vehicle batteries

The first category examines the interchange power between the vehicle and the network and the vehiclenetwork converter. According to the Balance Principle (KCL), the summation of exchanges between vehicle and network and the losses between vehicle and network converter must be zero. So we have:

$$
P_{E V}^{E t}=B_{E V}^{E, t}-P_{L E}^{E t} \quad \forall E \in S_{E}, t \in S_{t}
$$

where $P_{E V}$ is the injected power by the network to the vehicle (converter input) and ${ }^{B}{ }_{E V}$ is the minus loss power $\left(P_{L E}\right)$ at the converter output (electric vehicle battery injection). This schematic is $P_{E V+}{ }_{\text {if }}$ the electric vehicle is in the charge state and $P_{E V}-$ if it is in the discharge state. So at every hour for every vehicle we have:

$$
P_{E V}^{E, t}=P_{E V+}^{E, t}+P_{E V-}^{E, t} \quad \forall E \in S_{E}, t \in S_{t}
$$

Due to the efficiency between the vehicle and the network,

$\left(\Omega_{E V}\right)$, its rate of losses is calculated as follows:

$$
P_{L E}^{E, t}=\left(1-\Omega_{E V}\right)\left(P_{E V+}^{E, t}-P_{E V-}^{E, t}\right) \quad \forall E \in S_{E}, t \in S_{t}
$$


Depending on the power exchange infrastructure between the battery and the network, the maximum charge and discharge will be managed by the following equation:

$$
-B_{\text {max }}^{E} \leq B_{E V}^{E, t} \leq B_{\text {max }}^{E} \quad \forall E \in S_{E}, t \in S_{t}
$$

In order to indicate the status of the charge and discharge of electric vehicles, binary variables are considered.

$$
\begin{aligned}
& 0 \leq P_{E V+}^{E, t} \leq C_{\text {max }}^{E}\left(1-X_{E V}^{E, t}\right) \quad \forall E \in S_{E}, t \in S_{t} \\
& 0 \geq P_{E V-t}^{E, t} \geq-C_{\max }^{E} X_{E V}^{E, t} \quad \forall E \in S_{E}, t \in S_{t}
\end{aligned}
$$

The limitations for the energy balance of an electric vehicle are as follows:

$$
\begin{aligned}
& W_{E V}^{E, t}=W_{E V}^{0}+B_{E V}^{E, t} \quad \forall E \in S_{E}, t \in S_{t} \\
& W_{E V}^{E, t}=W_{E V}^{E, t-1}+B_{E V}^{E, t} \quad \forall E \in S_{E}, t \in S_{t}
\end{aligned}
$$

In other words, the energy stored in the battery is equal to the primary energy in the battery (when the vehicle is connected to the network) plus the energy exchanged with the network. The minimum energy stored in the battery is also limited as follows:

$$
W_{E V}^{E, t} \geq W_{\min }^{E} \quad \forall E \in S_{E}, t \in S_{t}
$$

\section{Demand response program constraints}

As explained in the previous section, two types of demand response programs including cost-sensitive and voltage-sensitive models are considered in the proposed model.

$$
\begin{aligned}
& P_{D R}^{i, \varphi, t}= \\
& \left(P_{D R 0}^{i, \varphi, t}\right)^{k 3-1}\left(P_{D R 0}^{i, \varphi, t}+\sum_{t \in S_{e}} E_{D R}^{t t} \frac{P_{D R 0}^{i, \varphi, t}}{\rho^{t}}\left(\rho^{t}-\rho^{t}\right)\right)^{k 1}\left(V^{i, \varphi, t}\right)^{k 1 k 2}
\end{aligned}
$$

According to the above equations, active loads are involved in both load response (voltage-sensitive and cost-sensitive) programs. In this formula, $\mathrm{k} 1, \mathrm{k} 2$, and $\mathrm{k} 3$ are binary variables. If the load is involved in the demand response program, then $k 3$ is equal to one, otherwise, it is equal to 0 . If $k 1$ is equal to one then 
the charge is cost-sensitive and if $k 2$ is equal to one, it is voltage-sensitive. According to the following equation, reactive power is only voltage-responsive.

$$
Q_{D R}^{i, \varphi, t}=\left(Q_{D R 0}^{i, \varphi, t}\right)^{k 3-1}\left(V^{i, \varphi, t}\right)^{\alpha \beta}
$$

The values of $a$ and $\beta$ are determined by the type of load according to the reference [21]. The following equations manage the minimum and maximum participation of loads in the demand response program.

$$
\begin{aligned}
& P_{\min }^{i, \varphi, t} \leq P_{D R}^{i, \varphi, t} \leq P_{\text {max }}^{i, \varphi, t} \\
& Q_{\text {min }}^{i, \varphi, t} \leq Q_{D R}^{i, \varphi, t} \leq Q_{\text {max }}^{i, \varphi, t}
\end{aligned}
$$

\section{Network technical constraints}

The network constraints which include the capacity of the lines and the voltage limitations of the buses are expressed in the following equations:

$$
\begin{aligned}
& V_{\min }^{i} \leq V^{i, \varphi, t} \leq V_{\text {max }}^{i} \\
& \left.\left(P^{(i, j), \varphi, t}\right)^{2}\right)^{2}+\left(Q^{(i, j), \varphi, t}\right)^{2} \leq C_{L}^{(i, j), \varphi}
\end{aligned}
$$

The values of $P^{(i, j), \varphi, t}$ and $Q^{(i, j), \varphi, t}$ are calculated by equations (2) and (3). The constraint of the voltage difference between the phases is applied to avoid instability and unbalance reduction in the proposed scheme. In other words, the voltage difference between the three phases A, B and C in the threephase distribution network is managed as follows:

$$
\begin{aligned}
& -\varepsilon \leq\left|V^{i, A, t}-V^{i, B, t}\right| \leq \varepsilon \\
& -\varepsilon \leq\left|V^{i, A, t}-V^{i, C, t}\right| \leq \varepsilon \\
& -\varepsilon \leq\left|V^{i, B, t}-V^{i, C t}\right| \leq \varepsilon
\end{aligned}
$$

Finally, according to the objective function, the amount of loss, active and reactive load of the whole system is calculated by the following equations: 


$$
\begin{aligned}
& P_{D R_{\text {Tots }}}^{t}=\sum_{\varphi \in S_{\varphi}} \sum_{i \in S_{i}} P_{D R}^{\varphi, i, t} \\
& P_{\text {Loss }}{ }^{t}=\sum_{\varphi \in S_{\varphi}} \sum_{i \in S_{i}} P_{G}^{\varphi, i, t}-\sum_{\varphi \in S_{\varphi}} \sum_{i \in S_{i}} P_{D R}^{\varphi, i, t}
\end{aligned}
$$

\section{Simulation and numerical results}

In order to evaluate the effectiveness of the proposed approach, the model is implemented on GAMS software on the low voltage distribution network and evaluated by various tests described later.

\section{Introducing test network}

The test network used in this study is the 37 buses low voltage network shown in the Fig. 1 . The voltage of this network is $400 \mathrm{~V}$ and its power reference is $100 \mathrm{kVA}$. The upstream nominal capacity is $800 \mathrm{kVA}$. The allowed voltage range is also 0.9 pu to $1.05 \mathrm{pu}$. The network loads are indoor and equipped with electric vehicle parking. The information on the maximum load of this network is shown in the Table 1. The load variations of the network during different hours of the day are shown in Fig. 2 based on the load factor. According to the concept of the load factor, the graph shows what coefficient of the network peak, the amount of load per hour is. Electricity prices are also divided into three tariffs. The three tariffs, according to the curve in Fig. 3, are the hours of low weak, intermediate load and hours of full load. The energy price based on \$ MWh is shown in the Fig. 4.

\section{Electric vehicles information}

The Information of electric Vehicles is divided into several distinct categories described as follows.

\section{Number of electric vehicles}

Here, it is assumed that vehicles are decentralized and distributed in residential parking lots. There are two EVs per network bus. With 25 residential buses in the network, there are a total of 150 electric vehicles in the network. 
Table 1

Test network load information

\begin{tabular}{|c|c|c|c|c|c|c|}
\hline \multirow{2}{*}{$\begin{array}{l}\text { Load } \\
\text { No. }\end{array}$} & \multicolumn{2}{|c|}{ Phase A } & \multicolumn{2}{|c|}{ Phase B } & \multicolumn{2}{|l|}{ B C } \\
\hline & $\begin{array}{l}\text { Active } \\
\text { power }\end{array}$ & $\begin{array}{l}\text { Reactive } \\
\text { power }\end{array}$ & $\begin{array}{l}\text { Active } \\
\text { power }\end{array}$ & $\begin{array}{l}\text { Reactive } \\
\text { power }\end{array}$ & $\begin{array}{l}\text { Active } \\
\text { power }\end{array}$ & $\begin{array}{l}\text { Reactive } \\
\text { power }\end{array}$ \\
\hline 27 & 4 & 3 & 5 & 2 & 6.4 & 2.5 \\
\hline 26 & 4.2 & 2.5 & 5 & 2 & 6 & 3 \\
\hline 14 & 5.2 & 3 & 3 & 2 & 4 & 2.5 \\
\hline 25 & 6.1 & 2.5 & 5.6 & 3 & 7 & 2 \\
\hline 13 & 7.1 & 2 & 8 & 1 & 7.5 & 1.5 \\
\hline 20 & 6.2 & 3 & 7 & 1 & 8 & 4 \\
\hline 5 & 5.1 & 3.2 & 8.4 & 4.2 & 9 & 3.4 \\
\hline 1 & 46.1 & 30 & 28 & 15 & 34 & 20 \\
\hline 7 & 8.3 & 3.2 & 8.3 & 4.1 & 9 & 3.3 \\
\hline 6 & 5.7 & 2.8 & 4 & 2 & 4.4 & 2.3 \\
\hline 8 & 6.2 & 3 & 7 & 3.5 & 8 & 4.5 \\
\hline 11 & 3.1 & 1.5 & 2.8 & 2 & 3.3 & 1 \\
\hline 15 & 6.2 & 2.6 & 7 & 3.5 & 8 & 4 \\
\hline 16 & 6.1 & 3 & 2.5 & 0.25 & 6 & 4 \\
\hline 9 & 1.2 & 0.6 & 3.3 & 0.9 & 5.5 & 0.7 \\
\hline 17 & 4.2 & 2.5 & 5 & 1 & 7 & 1.9 \\
\hline 23 & 8.2 & 3 & 2.5 & 0.25 & 6 & 4 \\
\hline 24 & 6.1 & 3.5 & 7.4 & 3.5 & 8 & 4 \\
\hline 28 & 4.1 & 1.55 & 5 & 1.2 & 6.5 & 1.65 \\
\hline 31 & 6.6 & 2 & 7.6 & 3 & 9 & 2.5 \\
\hline 32 & 4.1 & 1.5 & 7 & 1.1 & 8 & 0.5 \\
\hline 30 & 4.2 & 2 & 6 & 1.8 & 5.4 & 2.5 \\
\hline 33 & 4.1 & 2.6 & 7.2 & 1.6 & 4.8 & 1.8 \\
\hline 35 & 5.1 & 1 & 6 & 2.2 & 7 & 2.6 \\
\hline
\end{tabular}




\begin{tabular}{|lllllll|}
\hline $\begin{array}{l}\text { Load } \\
\text { No. }\end{array}$ & Phase A & \multicolumn{5}{c|}{ Phase B } \\
\cline { 2 - 7 } & $\begin{array}{l}\text { Active } \\
\text { power }\end{array}$ & $\begin{array}{l}\text { Reactive } \\
\text { power }\end{array}$ & $\begin{array}{l}\text { Active } \\
\text { power }\end{array}$ & $\begin{array}{l}\text { Reactive } \\
\text { power }\end{array}$ & $\begin{array}{l}\text { Active } \\
\text { power }\end{array}$ & $\begin{array}{l}\text { Reactive } \\
\text { power }\end{array}$ \\
\hline 36 & 6.1 & 3 & 8 & 2.4 & 7 & 3.5 \\
\hline Total & 173 & 89 & 172 & 69 & 199 & 84 \\
\hline
\end{tabular}

\section{Time of entrance and exit of vehicles}

This data depends on the behavior of the owners of electric vehicles. Following [21], it is assumed that each vehicle will be connected to the network after the last day of use. Vehicle network connection behavior at different times of the day is uncertain and must be modeled randomly. The behavior of electric vehicles in connection to the network is shown in the Fig. 4 according to the normal probability density function. According to the Fig. 5, the peak of the presence of EVs in the network overlaps with the peak load. According to these figures, the time of most exits of EVs from the network is between 5 am to $10 \mathrm{am}$.

\section{The amount of the energy consumption of electric vehicles battery throughout the day}

There is a direct relationship between energy consumption (EC) of electric vehicles and the distance traveled by them. The energy consumption of EV is calculated according to the following equations.

$$
\begin{aligned}
& S O C=\left(1-\frac{D}{A D}\right), \\
& \mathrm{EC}=(1-\mathrm{SOC}) \cdot C_{\text {max }}
\end{aligned}
$$

where $D$ is the traveled distance by EV (for hybrid vehicles solely in electric mode) and AD is the maximum distance that $\mathrm{EV}$ can go with a single charge. $C_{\max }$. is the maximum battery capacity and SOC is the charge state of the EV that expresses the amount of energy of the battery at each moment.

The relationship (31) is dependent on the distance traveled by the EV. The value of this distance is investigated by the normal probability density function addressed in reference [21]. According to this reference, electric vehicles travel an average of 25 to 30 miles per day.

\section{Technical information of EVs}

Technical information on EVs including efficiency, battery capacity and maximum charging rate is given in the Table 2. 
Table 2

Technical information of the studied electric

vehicle

\begin{tabular}{|ll|}
\hline Maximum EV Charging Rate & $\mathbf{4 . 6 5} \mathbf{~ k V A}$ \\
\hline Charging efficiency & 0.9 \\
\hline Battery capacity & $16 \mathrm{~kW}$ \\
\hline Full charge time & $4 \mathrm{~h}$ \\
\hline
\end{tabular}

\section{Information of demand response}

Two types of voltage-sensitive and cost-sensitive loads have been used in this study. For voltagesensitive loads, the coefficients $\alpha$ and $\beta$ are 0.92 and 4.04, respectively. Information on price-sensitive loads according to the load profile in Fig. 2, the energy price signals in Fig. 3, and the price elasticity are presented in Table 3.

Table 3

Cost of load transfer between different hours

\begin{tabular}{|llll|}
\hline Transfer interval & Low load hours & Intermediate hours & Full load hours \\
\hline Low load hours & 0.12 & 0.16 & -0.1 \\
\hline Intermediate hours & 0.01 & -0.1 & 0.16 \\
\hline Full load hours & -0.1 & 0.01 & 0.12 \\
\hline
\end{tabular}

\section{Investigation of the effect of EVs penetration into the network without the proposed strategy}

In this test, after connecting to the network, the EVs perform the charging process (G2V) immediately at maximum charge rate and they are fully charged after 4 hours based on the battery specifications. The number of vehicles connected to the network per hour is shown in Fig. 5. This test was conducted regardless of the smart charging and discharging strategy, and ignoring demand response.

The network power demand curve of the upstream network for power consumption is illustrated by changing the EV penetration level to values of $0 \%, 25 \%$ and $50 \%$.

According to this figure, unmanaged charging of EVs increases the network peak and consequently increases the power demand during peak hours of the upstream network. According to the network capacity limit (upstream post), lines and buses voltage, with a 50\% penetration level of electric vehicles, i.e 75 vehicles are connected to the network, the apparent power of the network reaches nominal power of $8 \mathrm{pu}$. In this situation, further vehicle connection is impossible. On the other hand, the network is at risk, and no capacity is left to cover any possible increase in load, thus the reliability of the network is reduced. 
Therefore, because of the significant increase in peak load, without a smart and controlled charging strategy, it is impossible to connect half of the vehicles. In order to connect these new loads, upgrading the network is needed, which requires considerable time and costs.

Naturally, as the peak load power increases, the bus voltage drop also increases relative to the EV-free mode. The effect of increasing the level of penetration of EVs in the network on the buses voltage drop is shown in Fig. 7. In this figure, bus number 1 is the reference bus and its voltage value is $1 \mathrm{pu}$. The increase in voltage drop in this form is quite obvious.

Since the load distribution is unbalanced between different phases, the voltage drop of each phase in each bus varies from other phases. In other words, there is an imbalance between phases. The voltage drop of the different phases in each bus is shown in the Fig. 8. According to this figure, the worst case of voltage drop is related to bus 36 , which is the farthest bus from the power supply, as shown in the Table 4 of values. This bus is considered in the following section as an indicator to investigate the effect of charge control of EVs on voltage drop.

Table 4

Voltage difference of bus 36 phases in different diffusion coefficients of EVs

\begin{tabular}{|llll|}
\hline Voltage difference & Penetration 0\% & Penetration 25\% & Penetration 50\% \\
\hline$A B$ & 2.1 & 1.7 & 1.3 \\
\hline$A C$ & 5.21 & 5.3 & 5.7 \\
\hline$B C$ & 3.3 & 3.7 & 4.5 \\
\hline
\end{tabular}

The amount of losses in the network is also shown in Table 5 for 24 hours. As expected, with the increase in loads due to the charging of EVs and consequently the increase in the line passing current, losses have also increased significantly.

Table 5

Losses (kwh) in the network at different diffusion coefficients of EVs

\begin{tabular}{|lll|}
\hline Penetration 0\% & Penetration 25\% & Penetration 50\% \\
\hline 39 & 47.8 & 58 \\
\hline
\end{tabular}

The network was evaluated technically in the above description. Economically, according to Fig. 3, the cost of power supply needed by the network in 24 hours based on the level of EV penetration is presented in theTable 6. Certainly, as the cost of purchasing energy is high during peak hours of consumption, the cost of supply has also increased considerably with the increase in peak demand. 
Table 6

cost of electricity $(\$)$ to supply the network load per day understudy of different penetration coefficients of EVs

\begin{tabular}{|lll|}
\hline 0\% penetration & 25\% penetration & penetration $\mathbf{5 0 \%}$ \\
\hline 198.54 & 214.36 & 230.6 \\
\hline
\end{tabular}

\section{Investigating the effect of EVs penetration into the network without charge control strategy and with regard to demand response management}

In this test, the effect of demand response management program on the network performance is evaluated. Since this study applies two types of voltage-sensitive and cost-sensitive loads, this section is divided into three sub-sections to investigate the effectiveness of each demand management program. In the first section, only voltage-sensitive loads are considered. In the second sub-section, price-sensitive loads and in the third sub-section, both types of loads are considered. The effect of each management strategy on the network parameters is discussed below.

\section{Voltage- sensitive loads management}

In this case, the coefficients $\mathrm{k} 1$ and $\mathrm{k} 2$ are considered to be 0 and 1 respectively. In this section, reactive and active loads are considered as decision variables in the optimization problem. The power demand variations of the network respect to the different penetration levels are shown in Fig. 9.

According to the figure, the management of voltage-sensitive loads lonely does not have much impact on the release of micro-grid capacity and the increase in EVs penetration coefficient. Managing these loads reduces the apparent network power slightly at all hours, and consequently increases the EVs penetration to $4 \%$. Lack of network capacity for connecting all the electric vehicles, lack of free network capacity, and dramatically increased peak load are still evident. Therefore, managing these loads does not affect the daily load curve greatly.

Fig. 10 shows the effect of management of all this loads on the voltage drop of the network. According to this figure, the management of these loads has reduced the voltage drop of the network.

The voltage difference between the different phases is expressed in bus 36 in Table 7 and network losses is expressed in Table 8. 
Table 7

Voltage difference of bus 36 phases in different diffusion coefficients of EVs

\begin{tabular}{|lllll|}
\hline $\begin{array}{l}\text { Voltage } \\
\text { difference }\end{array}$ & $\begin{array}{l}\text { Penetration } \\
\mathbf{0 \%}\end{array}$ & $\begin{array}{l}\text { penetration } \\
\mathbf{2 5 \%}\end{array}$ & $\begin{array}{l}\text { Penetration } \\
\mathbf{5 0 \%}\end{array}$ & $\begin{array}{l}\text { Penetration } \\
\mathbf{5 4 \%}\end{array}$ \\
\hline $\mathrm{AB}$ & 2.1 & 1.7 & 1.3 & 1.3 \\
\hline $\mathrm{AC}$ & 5.21 & 4.1 & 5.3 & 5.3 \\
$\mathrm{BC}$ & 3.3 & 2.4 & 4.1 & 4.1 \\
\hline
\end{tabular}

Table 8

Losses (kwh) in the network at different diffusion coefficients of EVs

\begin{tabular}{|lll|}
\hline penetration $\mathbf{0 \%}$ & penetration $\mathbf{5 0 \%}$ & penetration $\mathbf{5 4 \%}$ \\
\hline 37 & 54 & 55 \\
\hline
\end{tabular}

In order to better evaluate the effectiveness of voltage-sensitive load management, a comparison between the results of the previous section with this section at a constant penetration level of $50 \%$ for EV is presented in Table 9. According to this table, peak load power has been reduced by $2.5 \%$, which has increased the EV penetration rate by $4 \%$. On the other hand, network losses have been dropped by about 7 percent. Buses voltage drop and the voltage difference between phases, which reflects network imbalance, have also been reduced.

\section{Cost-sensitive loads management}

In this case the coefficients $\mathrm{k} 1$ and $\mathrm{k} 2$ are considered as 1 and 0 , respectively. In this subsection, active load and energy price are considered as decision variables in the optimization problem. The management of the power demand variations of the network with respect to different penetration levels is shown in Fig. 11. 
Table 9

Improvement in percentage of network parameters at $50 \%$ constant penetration coefficient

\begin{tabular}{|llllc|}
\hline Title & $\begin{array}{l}\text { Voltage difference between } \\
\text { phase A and C ( })\end{array}$ & $\begin{array}{l}\text { Network bus } \\
\text { voltage (pu) }\end{array}$ & $\begin{array}{l}\text { Network } \\
\text { losses } \\
\text { (kWh) }\end{array}$ & $\begin{array}{l}\text { Power } \\
\text { (pu) }\end{array}$ \\
\hline $\begin{array}{l}\text { Without demand } \\
\text { response }\end{array}$ & 5.6 & 0.924 & 58 & 8 \\
\hline $\begin{array}{l}\text { With demand } \\
\text { response }\end{array}$ & 5.2 & 0.927 & 54 & 7.8 \\
\hline $\begin{array}{l}\text { Improvement } \\
\text { percentage }\end{array}$ & 7.15 & 0.32 & 7 & 2.5 \\
\hline
\end{tabular}

According to this figure, the management of cost-sensitive loads has increased the penetration rate of electric vehicles up to $22 \%$. This increased penetration states the efficiency of the proposed management approach on the reduction of peak load. However, the network still needs to be developed to supply all 150 electric vehicles, and the surplus power of the network, to cope with the possible power increase, which is equal to 0 .

Fig. 12 shows the effect of the management of these loads on the voltage drop of the network. According to this figure, the management of these loads has reduced the voltage drop of the network. This reduction is less than the previous state (voltage-sensitive load management).

The voltage difference between the different phases is expressed in bus 36 in Table 10 and the network losses is expressed in Table 11.

Table 10

Voltage difference of bus 36 phases in different diffusion coefficients of EVs

\begin{tabular}{|lllll|}
\hline Voltage difference & $\begin{array}{l}\text { penetration } \\
\mathbf{0} \%\end{array}$ & $\begin{array}{l}\text { penetration } \\
\mathbf{2 5 \%}\end{array}$ & penetration $\mathbf{5 0 \%}$ & penetration 73\% \\
\hline AB & 2.1 & 1.3 & 0.4 & 0.5 \\
\hline AC & 5.21 & 4.1 & 4.9 & 5.7 \\
\hline BC & 3.3 & 2.9 & 4.5 & 5.3 \\
\hline
\end{tabular}

Table 11

Losses (kwh) in the network at different DIFFUSION coefficients of EVs

\begin{tabular}{|lll|}
\hline 0\% penetration & penetration $\mathbf{5 0 \%}$ & penetration $\mathbf{7 3 \%}$ \\
\hline 36 & 54 & 64 \\
\hline
\end{tabular}

Page 18/40 
In order to perform a better evaluation of the efficiency constant of voltage-sensitive load management, a comparison between the results of the previous section with this section at a penetration level of $50 \%$ for EV is presented in Table 12. According to this table, peak load power has been reduced by about $12 \%$, which has increased the EV penetration coefficient by $22 \%$. This reduction of the peak is remarkable. Network losses, on the other hand, decrease to about 7 percent. Buses voltage drop and the voltage difference between phases which causes network unbalance have also been reduced.

Table 12

Improvement percent of network parameters at 50\% constant penetration coefficient

\begin{tabular}{|llllc|}
\hline Title & $\begin{array}{l}\text { Voltage difference between } \\
\text { phase A and C ( })\end{array}$ & $\begin{array}{l}\text { Network bus } \\
\text { voltage }(\mathbf{p u})\end{array}$ & $\begin{array}{l}\text { Network } \\
\text { losses } \\
(\mathbf{k W h})\end{array}$ & $\begin{array}{l}\text { Power } \\
(\mathbf{p u})\end{array}$ \\
\hline $\begin{array}{l}\text { Without demand } \\
\text { response }\end{array}$ & 5.6 & 0.924 & 58 & 8 \\
\hline $\begin{array}{l}\text { With demand } \\
\text { response }\end{array}$ & 4.8 & 0.93 & 54 & 7 \\
\hline $\begin{array}{l}\text { Improvement } \\
\text { percent }\end{array}$ & 14 & 0.76 & 7 & 11.85 \\
\hline
\end{tabular}

Since the influence of electric vehicles has a great impact on peak load and on the other hand, the cost of the power supply is high during peak hours, the management of cost-sensitive loads, in comparison with voltage-sensitive loads, is much more effective on improving network parameters.

\section{Simultaneous management of cost -sensitive and voltage- sensitive loads}

In this case, the coefficients $\mathrm{k} 1$ and $\mathrm{k} 2$ are both equal to 1 . Here, active load, reactive load, and energy price are considered as decision variables in the optimization problem. According to different penetration levels, managing power demand variations of the network according to different penetration levels is shown in Fig. 13.

According to this figure, the management of cost and voltage-sensitive loads has increased the penetration rate of electric vehicles up to $25 \%$. This increase in penetration is higher than the previous two cases, and indicating DR's effectiveness in significantly reducing peak load. However, the network still must be expanded to supply all 150 electric vehicles, while the network surplus capacity to cope with potential increases is zero.

Fig. 14 shows the effect of the management of these loads on the voltage drop of the network. According to this figure, the management of these loads has reduced the voltage drop of the network. This reduction is less than the previous ones (managing voltage-sensitive and cost-sensitive loads alone). 
The voltage difference between the different phases is stated in bus 36 in Table 13 and the network losses are stated in Table 14.

Table 13

Voltage difference of bus 36 phases in different diffusion coefficients of EVs

\begin{tabular}{|llll|}
\hline Voltage difference & Penetration 0\% & Penetration 25\% & Penetration 75\% \\
\hline AB & 1.2 & 0.8 & 0.14 \\
\hline AC & 3.7 & 4.4 & 5.2 \\
\hline BC & 2.4 & 4 & 4.80 \\
\hline
\end{tabular}

Table 14

Losses (kwh) in the network at different diffusion

coefficients of EVs

\begin{tabular}{|lll|}
\hline 0\% penetration & 25\% penetration & penetration $75 \%$ \\
\hline 33 & 50 & 61 \\
\hline
\end{tabular}

In Table 15, a comparison between the results of the previous section with this section at a constant penetration level of $50 \%$ for $E V$ is performed to evaluate the effectiveness of managing voltage-sensitive loads. According to this table, peak load power has been reduced by about $14 \%$, which has increased the EV penetration rate by $25 \%$. This reduction in peak is considerable. Network losses, on the other hand, have decreased to 13 percent. This demonstrates the remarkable impact of load management on reducing network losses. Buses voltage drop and voltage difference between phases which indicate network unbalancing have also been reduced so that the voltage imbalance between different phases is improved up to $21 \%$.

Table 15

Improvement percent of network parameters at $50 \%$ constant diffusion coefficient

\begin{tabular}{|llllc|}
\hline Title & $\begin{array}{l}\text { Voltage difference between } \\
\text { phase A and C ( })\end{array}$ & $\begin{array}{l}\text { Network bus } \\
\text { Voltage }(\mathrm{pu})\end{array}$ & $\begin{array}{l}\text { Network } \\
\text { losses } \\
\mathbf{( k W h )}\end{array}$ & $\begin{array}{l}\text { Power } \\
(\mathrm{pu})\end{array}$ \\
\hline $\begin{array}{l}\text { Without demand } \\
\text { response }\end{array}$ & 5.6 & 0.924 & 58 & 8 \\
$\begin{array}{l}\text { With demand } \\
\text { response }\end{array}$ & 4.4 & 0.93 & 50 & 6.9 \\
\hline $\begin{array}{l}\text { Improvement } \\
\text { percentage }\end{array}$ & 21 & 0.76 & 13 & 13.35 \\
\hline
\end{tabular}


As it can be seen from the results of this section, it is true that the DR program is very effective in improving network parameters but it alone cannot manage this level of penetration of EVs in the network. In the above description, the network was evaluated technically. Economically, according to the Fig. 3, the cost of power supply needed by the network in 24 hours based on the level of EV penetration is presented in Table 16. As the cost of purchasing energy is high during peak hours of consumption, due to transfer some part of the load from low-load to full-load, the cost of load supply is also reduced by applying a demand response management strategy.

Table 16

Cost of electricity (\$) to supply the grid load per day under study of different diffusion coefficients of EVs

\begin{tabular}{|llll|}
\hline & $\begin{array}{l}\text { Penetration } \\
\mathbf{0 \%}\end{array}$ & $\begin{array}{l}\text { Penetration } \\
\mathbf{2 5 \%}\end{array}$ & $\begin{array}{l}\text { Penetration } \\
\mathbf{7 5 \%}\end{array}$ \\
\hline Without demand response & 198.54 & 360.6 & - \\
\hline With demand response & 188 & 223 & 242 \\
\hline $\begin{array}{l}\text { Improvement percentage } \\
\text { Investigating the effect of Evs penetration on the network by the proposed charge control strategy } \\
\text { along with demand response management }\end{array}$ & 137 \\
\hline
\end{tabular}

This test considers the strategy of charging and discharging electric vehicles along with managing loads. According to the proposed charging strategy, vehicles can be charged and discharged, which means they operate in V2G and G2V and they do not charge as soon as they are connected to the network. Charging and discharging operations are managed based on the network parameters and set of objectives in the previous section. Due to the high energy price during peak hours of consumption and increased losses and voltage drop due to high demand, the control strategy in these hours is to discharge operations and to charge vehicles during low load hours.

It should be noted that charging and discharging operations depend on the vehicle being connected to the network. Therefore, the vehicle may not be possible to charge in some hours of the day despite the lowload network, because it is not connected to the network. As explained in the previous section, the study is based on the assumption that the vehicles leave the network between 5 am and 10 am and they navigate the route at this time.

In addition to the charging and discharging strategy, price and voltage- sensitive loads have also been used to improve the network parameters in this test. Therefore, the decision variables in this test, in addition to the active and reactive loads, are also the active power stored in the EVs battery.

Given the $100 \%$ penetration coefficient (150 vehicles), the total number of vehicles connected to the network for different hours of the day is shown in Fig. 15. 
The start time of the simulation process in this test is $10 \mathrm{am}$. Since the objective function consists of three parts, voltage drop and imbalance between phases, cost of power consumption and losses and cost of energy supply of EVs, therefore, the weighting coefficients of the objective function must also be adjusted. These coefficients are set so that the amount of changes in each part of the objective function is equal to each other. In other words, the degree of importance of all three parts is the same. For this purpose, the distance between the minimum and maximum values of each part of the objective function must be equal to the other parts. The weighting coefficients are obtained from the following equations, where $F^{\min }$ and $F^{\max }$ are the minimum and maximum values of the objective function, respectively, and the indices 1, 2, and 3 represent the deviations of voltage, charge supply and loss cost, and energy supply cost of EVs, respectively. So, the weighting coefficients are obtained from the following equations.

$$
\begin{aligned}
& \frac{\omega_{1}}{\omega_{2}}=\frac{F_{1}^{\text {max }}-F_{1}^{\text {min }}}{F_{2}^{\text {max }}-F_{2}^{\text {min }}}, \\
& \frac{\omega_{1}}{\omega_{3}}=\frac{F_{1}^{\text {max }}-F_{1}^{\text {min }}}{F_{3}^{\text {max }}-F_{3}^{\text {min }}}
\end{aligned}
$$

According to the above explanations and relationships, the coefficients $\omega_{1}, \omega_{2}$ and $\omega_{3}$ are considered as $1,0.12$ and 0.17 , respectively. The network demand load with the maximum diffusion coefficient of the EVs and considering the load response is shown in Fig. 16.

According to this figure, by applying the proposed strategy, unlike the two previous tests, it is possible to connect all vehicles (100\% penetration coefficient) without imposing very high costs for network development. In addition, the effect of the proposed strategy in flattening the load curve is quite evident.

Depending on their presence, EVs charge between hours 12 and 17. They perform discharge operations in the full-load hours to reduce power costs and help improve network parameters. This has caused a reduction of the peak load consumption or clipping peak of the load curve due to EV discharge during peak hours, and valley filling due to discharge during low and intermediate load hours. By this proper management, not only is the need for network expansion to supply new loads is eliminated but also some network capacities remain empty despite the connection of all EVs. This residual capacity increases the reliability of power supply, especially in conditions of unexpected increases in demand. 
Table 17

Voltage difference of 36 bus phases at $20 \mathrm{~h}$ (peak load) and energy losses at $100 \%$ EVs penetration coefficient

\begin{tabular}{|llll|}
\hline $\begin{array}{l}\text { Energy losses } \\
(\mathrm{kWh})\end{array}$ & \multicolumn{2}{l}{ Phase to Phase } & Voltage difference $(\mathrm{V})$ \\
\cline { 2 - 4 } & BC & AC & AB \\
\hline 40 & 1.5 & 3 & 1.2 \\
\hline
\end{tabular}

The value of the voltage amplitude is shown in Fig. 17as a per unit in the various buses. Table 17 also shows the phases voltage and the amount of losses. According to these results, despite the $100 \%$ penetration of electric vehicles in the network and the significant load being added at different times, the rate of loss, voltage drop and imbalance between phases have decreased as peak power consumption. The amount of loss at $0 \%$ penetration rate was $39 \mathrm{kWh}$ (according to the first test), with 150 vehicles connected to the network, the amount of losses was only about $2 \mathrm{kWh}$, indicating the efficiency of the proposed model in reducing losses. It should be noted that according to the first test, if the proposed strategy was not used, only 75 vehicles would increase the amount of losses by about $20 \mathrm{kWh}$.

In addition to the losses, even with 150 vehicles connected to the network, the imbalance between phases is significantly reduced compared to 0 penetration levels.

In the above description, the network was evaluated technically. Economically, according to the figure, the cost of power supply needed by the network in 24 hours for various tests and based on the maximum EV penetration level is presented in Table 18. The results of this table illustrate the effectiveness of the proposed method. Given that the proposed strategy plays an effective role in flattening the load curve (shifting the load from full load to intermediate and low load) and on the other hand, the cost of purchasing energy is high during peak hours, the cost of supplying the load will reduce a lot by 150 vehicles connected to the network and a significant increase in load, much less. This is the concept of turning the challenge into an opportunity. The results showed that by properly managing the penetration of electric vehicles along with responsive loads, not only the network parameters were not compromised and the penetration of all the vehicles was managed without the need for network development, but also by applying the proposed strategy, the network parameters were improved. 
Table 18

Comparison of cost and maximum penetration rate of EVs and maximum peak load in different tests

\begin{tabular}{|llll|}
\hline $\begin{array}{l}\text { Without demand response program } \\
\text { (First test) }\end{array}$ & $\begin{array}{l}\text { Amount of the } \\
\text { network peak } \\
\text { (pu) }\end{array}$ & $\begin{array}{l}\text { Cost of } \\
\text { energy } \\
\text { supply } \\
\mathbf{( \$ )}\end{array}$ & $\begin{array}{l}\text { Maximum } \\
\text { penetration } \\
\text { rate }\end{array}$ \\
\hline $\begin{array}{l}\text { Alone with the proposed response program } \\
\text { (Second Test, Part 3) }\end{array}$ & 8 & 530.6 & $\begin{array}{l}50 \% \\
75 \mathrm{EVs}\end{array}$ \\
\hline $\begin{array}{l}\text { With the proposed strategy (charge and discharge } \\
\text { management and responsive demands) } \\
\text { (Third Test) }\end{array}$ & 8 & 242 & $\begin{array}{l}75 \% \\
112 \mathrm{EVs}\end{array}$ \\
\hline $\begin{array}{l}\text { Without demand response program } \\
\text { ((First Test }\end{array}$ & 5.05 & 185 & $\begin{array}{l}100 \% \\
150 \mathrm{EVs}\end{array}$ \\
\hline
\end{tabular}

\section{Conclusion}

In this study, a comprehensive management strategy has been introduced to manage the penetration of electric vehicles along with demand response. The strategy followed several goals, including reducing the cost of supply of power and load, reducing the cost of charging EVs, and improving network parameters, including voltage and imbalance between phases. According to the results, the proposed approach has made the challenge of the penetration of electric vehicles an opportunity to improve network parameters and even reduce the cost of energy supply. Managing the charge of EVs at low load and intermediate load times and using the remaining energy in the EVs battery during the full load hours, along with the cost-sensitive load management program will lead to a great reduction of the cost of power supply. On the other hand, decreasing the network peak and load distribution at different times along with the management of voltage-sensitive loads has resulted in an unbalanced improvement between the phases and the voltage drop, especially at the terminal buses of the network. As it can be seen from the results, without the proposed approach, it is impossible to manage the penetration of all EVs without network development. In addition, with the same level of penetration, the network capacity is completely occupied, which, in addition to reducing reliability, has a negative impact on the network parameters. The effectiveness of the proposed approach is fully supported by the results.

\section{Declarations}

Competing interests

The authors declare that they have no competing interests.

Funding

This work was funded by no organization.

Authors' contributions 
The paper is based on collective work, and all authors contributed to all parts.

Authors' information

Alireza Bakhshinejad is a member of the faculty of Electrical Engineering at Islamic Azad University Soumersara, Soumesara, Iran. His interests include industrial energy management, power system operation and power system planning. Abdolreza Tavakoli is a Professor of power engineering in the Department of Mathematics, Lahijan Branch, Islamic Azad university, Lahijan, Iran. His interests include industrial power network design and power system design and power electronics. Maziar Mihosseini Mogaddam works as an assistant professor in Lahijan branch, Islamic Azad University, Iran. His research interests include energy management, power system operation and power system planning.

Availability of data and materials

This research relied on research results obtained during the experiment and in the literature.

Ethics approval and consent to participate

Not applicable.

Consent for publication

Not applicable.

\section{References}

1.

Momen F, Rahman K, Son, Y.J.I.T.o.I.A (2019) Electrical propulsion system design of Chevrolet Bolt battery-electric vehicle. IEEE Transactions on Industry ApplicationsVol 55(1):376-384

2.

Yan Q, Zhang B, Kezunovic M (2018) Optimized Operational Cost Reduction for an EV Charging Station Integrated with Battery Energy Storage and PV generation. IEEE Transactions on Smart Grid.Vol.10(2) 3.

Wahid S (2019) Assessing electric vehicles charging via packetized management systems Master's thesis. Industrial Engineering and Management Global Management of Innovation and Technology. LUT University

4.

Bracale A, Caramia P, Proto D (2011) Optimal operation of smart grids including distributed generation units and plug -in vehicles. International Conference on Renewable Energies Power Quality (ICREPQ'11), Spain

5 .

Mehta R et al (2018) Smart charging strategies for optimal integration of plug-in electric vehicles within existing distribution system infrastructure. IEEE Transaction on Smart Grid 9(1):299-312

6.

Dharmakeerthi C et al (2014) Impact of electric vehicle fast-charging on power system voltage stability. International Journal of Electrical power ana Energy Systems 57:241-249 
7.

Teng $\mathrm{F}$ et al (2017) Challenges on primary frequency control and potential solution from EVs in the future GB electricity system. Applied Energy. vol. 194, pp 353-362

8.

Amini MH et al (2017) Simultaneous allocation of electric vehicles' parking lots and distributed renewable resources in smart power distribution networks. Sustainable cites Society vol 28:332-342

9.

Agüero JR et al. (2012)Integration of plug-in electric vehicles and distributed energy resources on power distribution systems. Electric Vehicle Conference (IEVC), 2012 IEEE International 10 .

Masoum AS et al (2014) Online coordination of plug-in electric vehicle charging in smart grid with distributed wind power generation systems, Power and Energy society PES General Meeting Conference \& Exposition, 2014 IEEE

11.

Jimenez A, Garci N (2011) Power flow modeling and analysis of voltage source converter-based plug-in electric vehicles. Power and Energy Society IEEE General Meeting, 2011 IEEE, 2011

12.

Masoum MA, Moses PS, Hajforoosh S (2012) Distribution transformer stress in smart grid with coordinated charging of plug-in electric vehicles. IEEE PES Innovative Smart Grid Technologies (ISGT) 13.

Rutherford MJ, Yousefzadeh V (2011)The impact of electric vehicle battery charging on distribution transformers. Applied Power Electronics Conference and Exposition (APEC), 2011 Twenty-Sixth Annual IEEE

14.

Sortomme E et al (2011) Coordinated charging of plug-in hybrid electric vehicles to minimize distribution system losses. Power and Energy Society Conference,2011 IEEE General Meeting. vol. 2(1), pp 198-205 15 .

Wenge $C$ et al (2012) Electric vehicle simulation models for power system applications. Power and Energy Society General Meeting Conference, 2012 IEEE

16.

Zhang S et al (2014) The influence of the electric vehicle charging on the distribution network and the solution. Transportation Electrification Asia-Pacific (ITEC Asia-Pacific), 2014 IEEE Conference and Expo 17.

Mozafar MR et al (2017) A simultaneous approach for optimal allocation of renewable energy sources and electric vehicle charging stations in smart grids based on improved GA-PSO algorithm. Sustainable cites Society vol 32:627-637

18.

Yao L, Lim WH, Tsai T.S.J.I.T.o.S G (2016) A real-time charging scheme for demand response in electric vehicle parking station. IEEE Transactions on Gride 8(1):52-62

19. 
Shi $Y$ et al (2018) Model predictive control for smart grids with multiple electric-vehicle charging station. IEEE Transactions on Smart Grid. vol. 10(2)

20.

Moghaddam Z et al (2018) Smart Charging Strategy for Electric Vehicle Charging Stations. IEEE Transactions on Transportation Electrification 4(1):76-88

21.

Shafiee S, Fotuhi-Firuzabad M, Rastegar MJ, I. T., O. S. Investigating the impacts of plug-in hybrid electric vehicles on power distribution systems, IEEE Transactions on smart Gride. vol. 4(3), pp. 1351-1360, 20

\section{Figures}

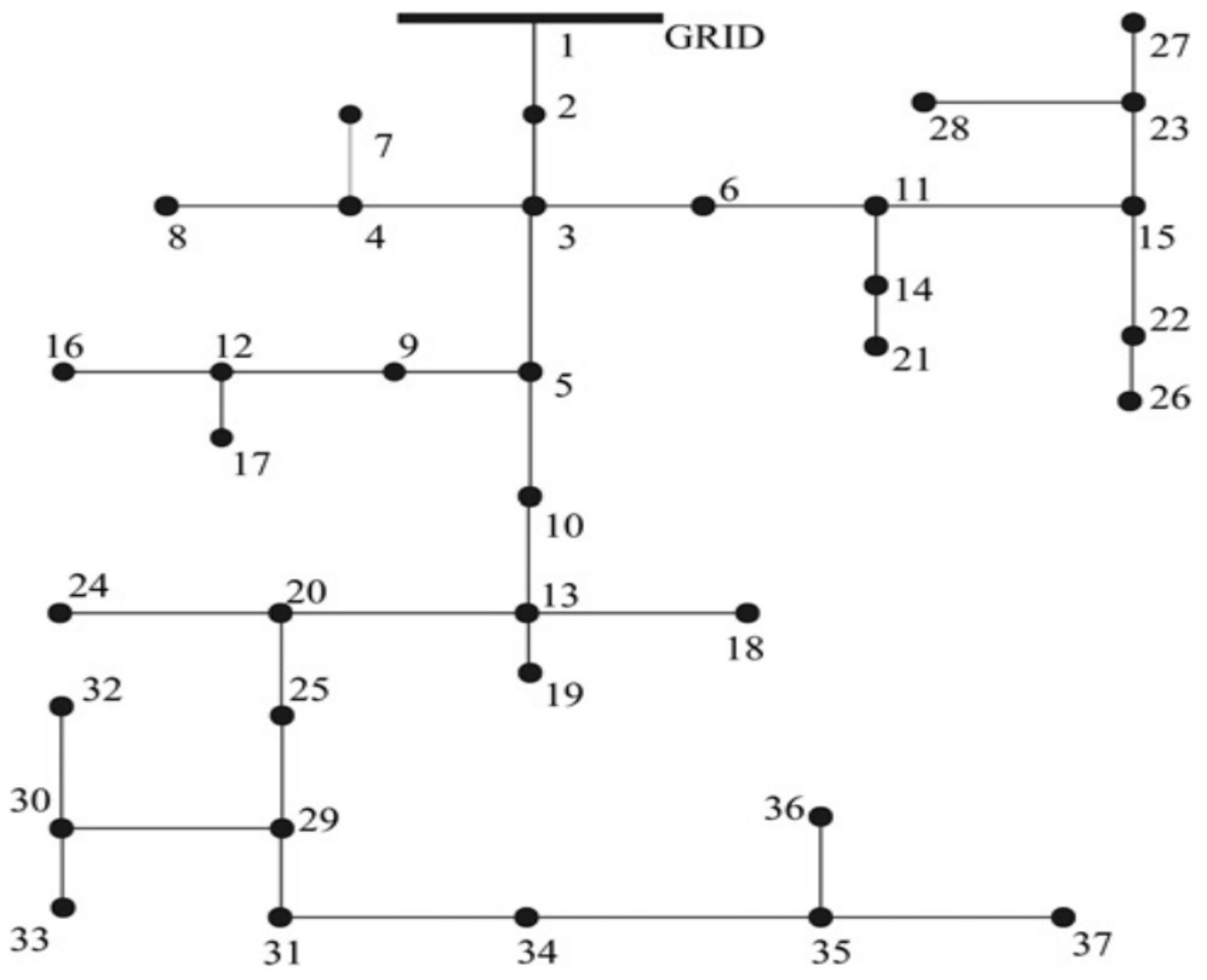

\section{Figure 1}

The studied network (37 IEEE buses) 


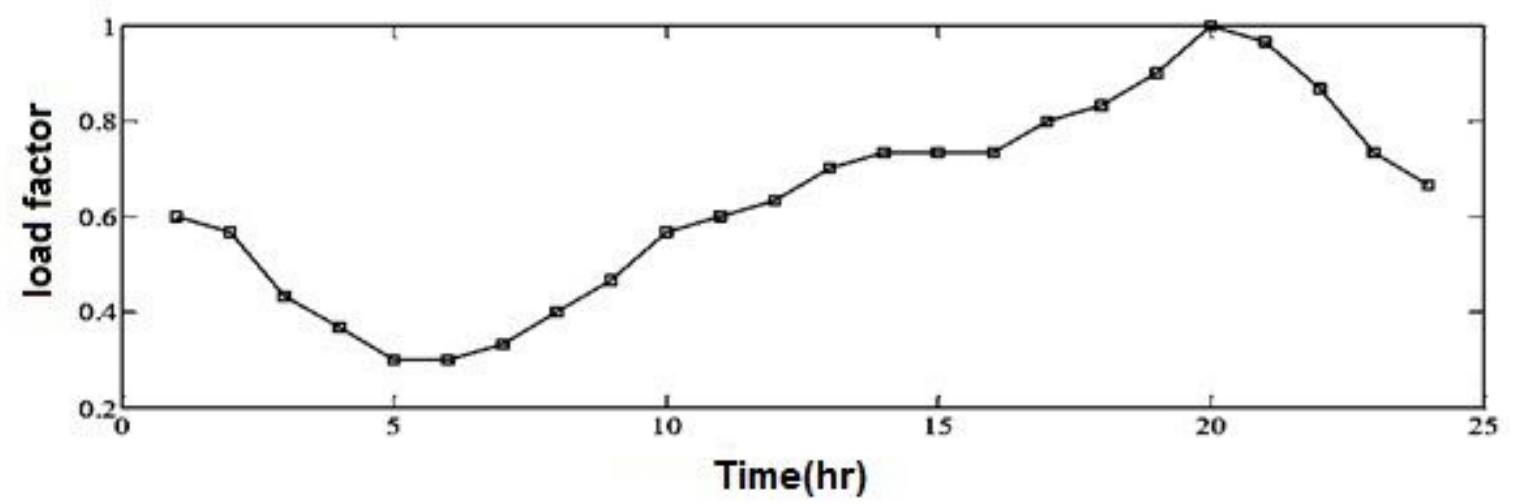

Figure 2

Load coefficient 24 hours a day

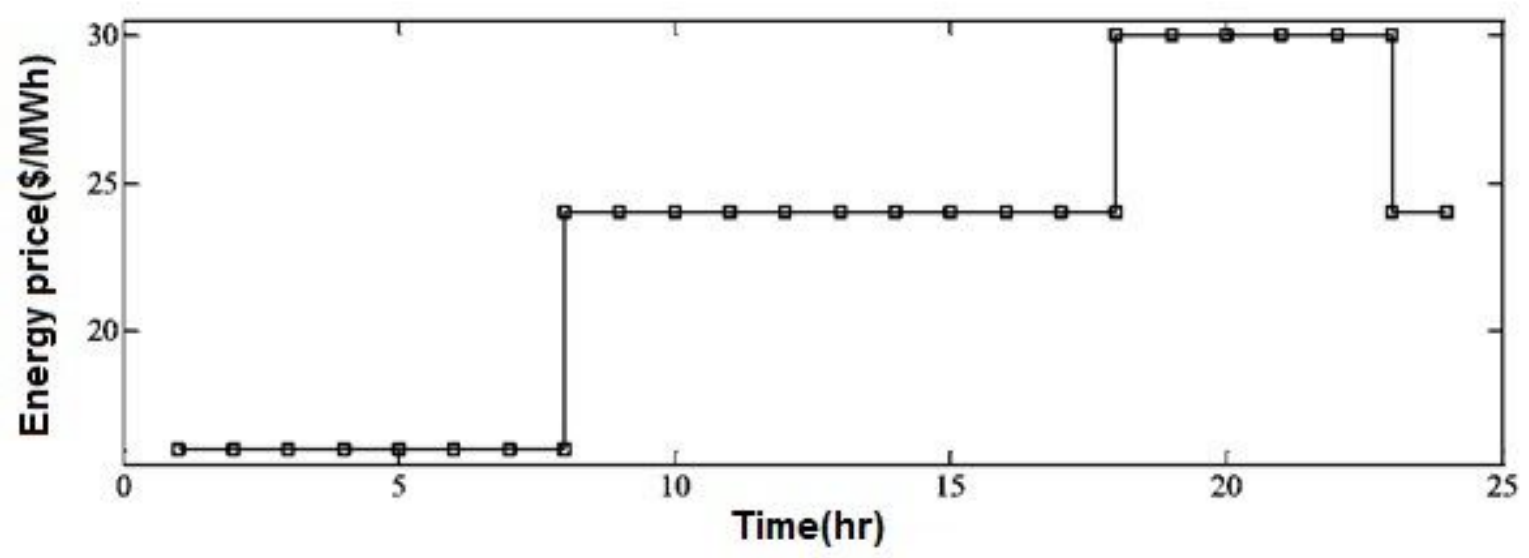

Figure 3

Hourly electricity price 


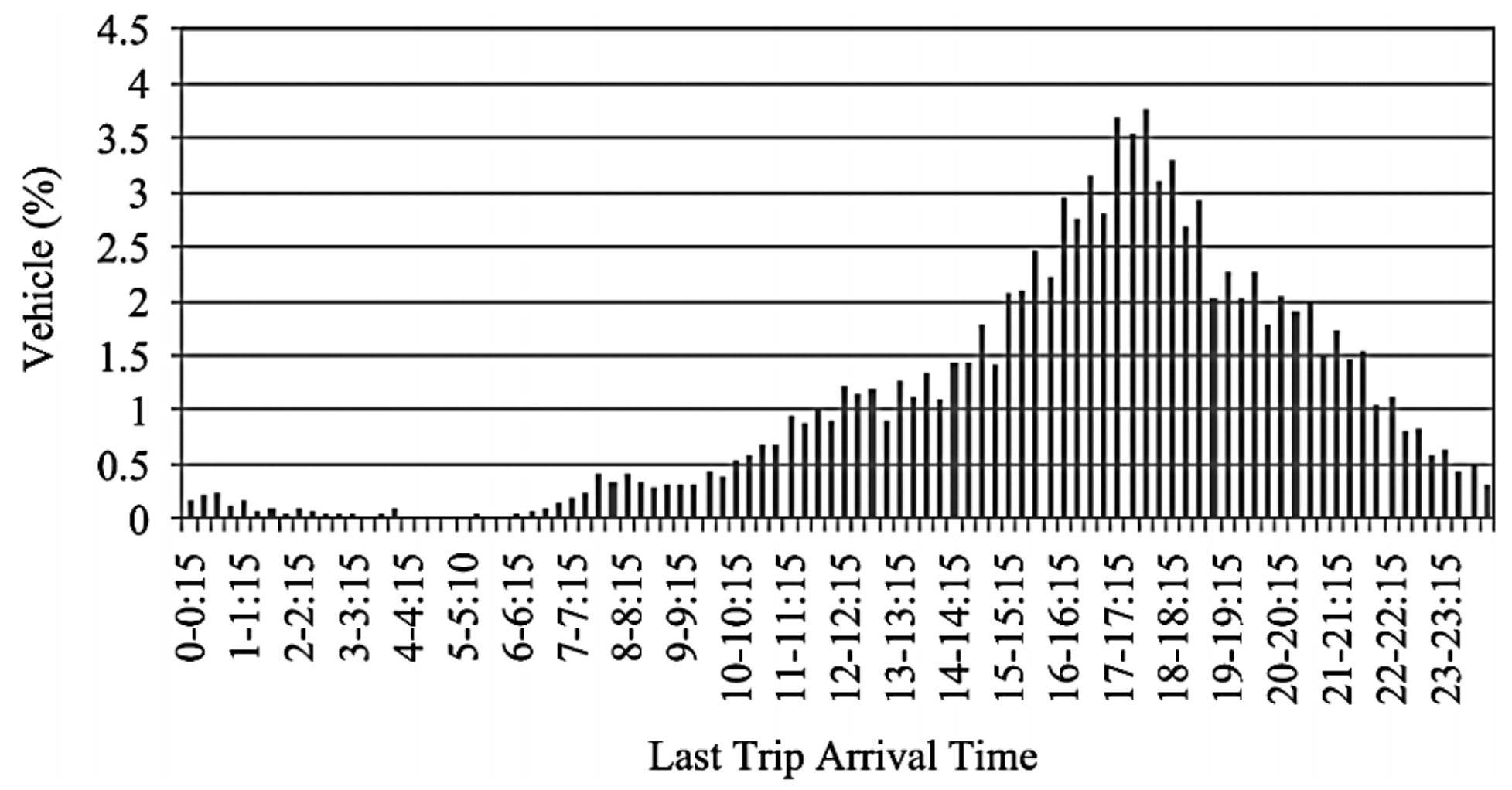

Figure 4

An example of the presence of the electric vehicles at different hours of a day[21]

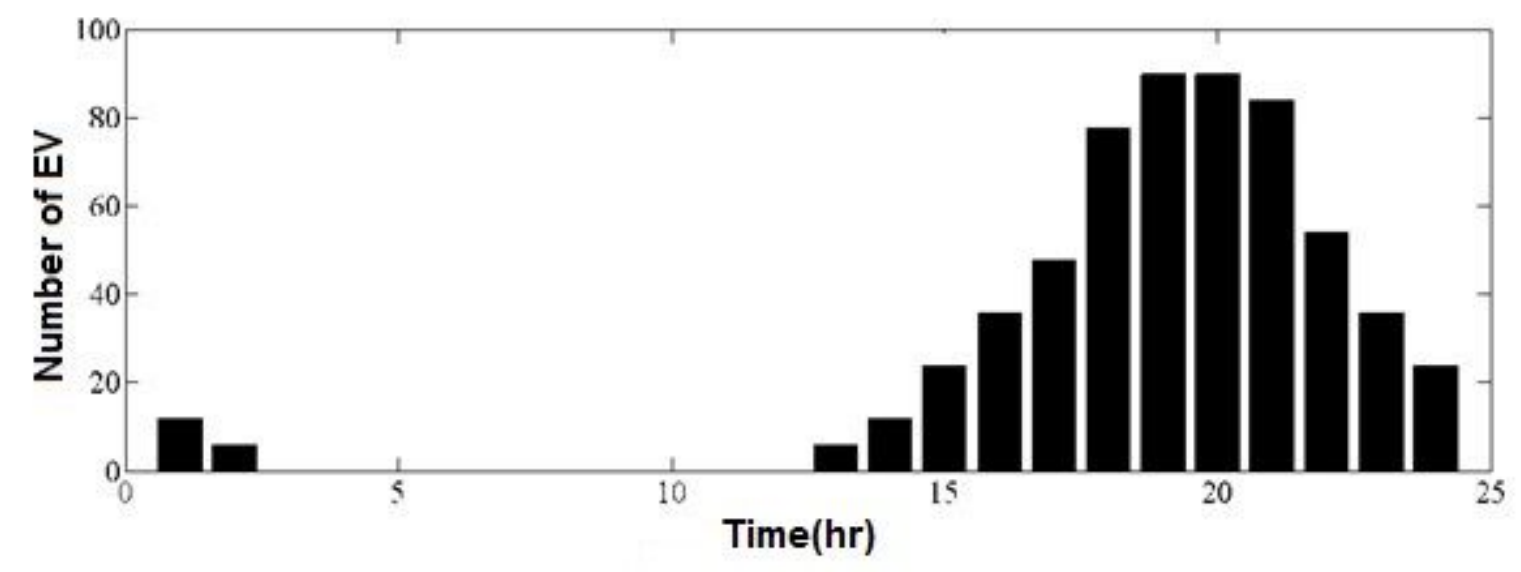

Figure 5

Number of vehicles connected to the network at different times based on maximum penetration coefficient 


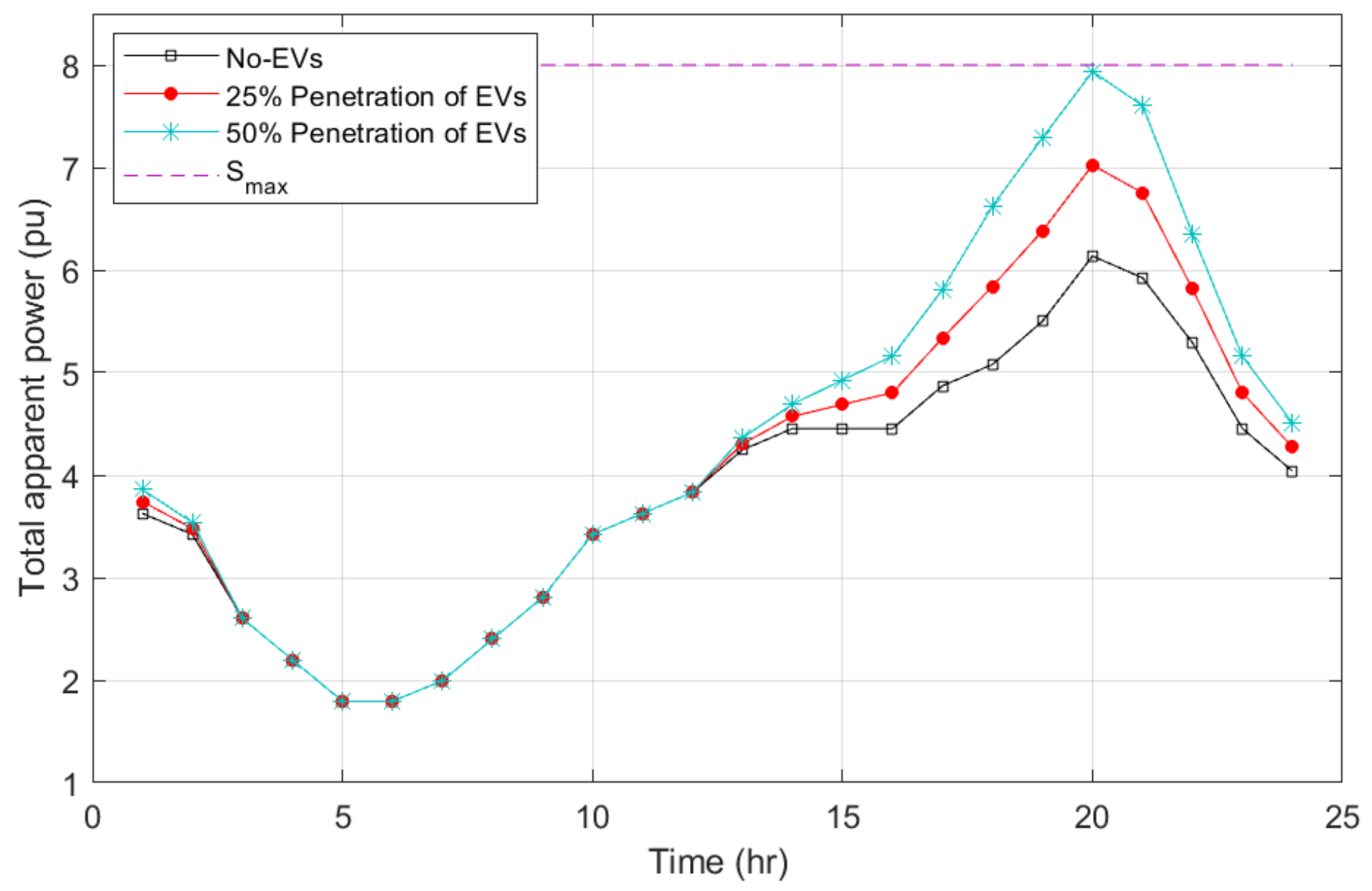

Figure 6

Hourly demanded network power (load profile) at various EV diffusion coefficients 


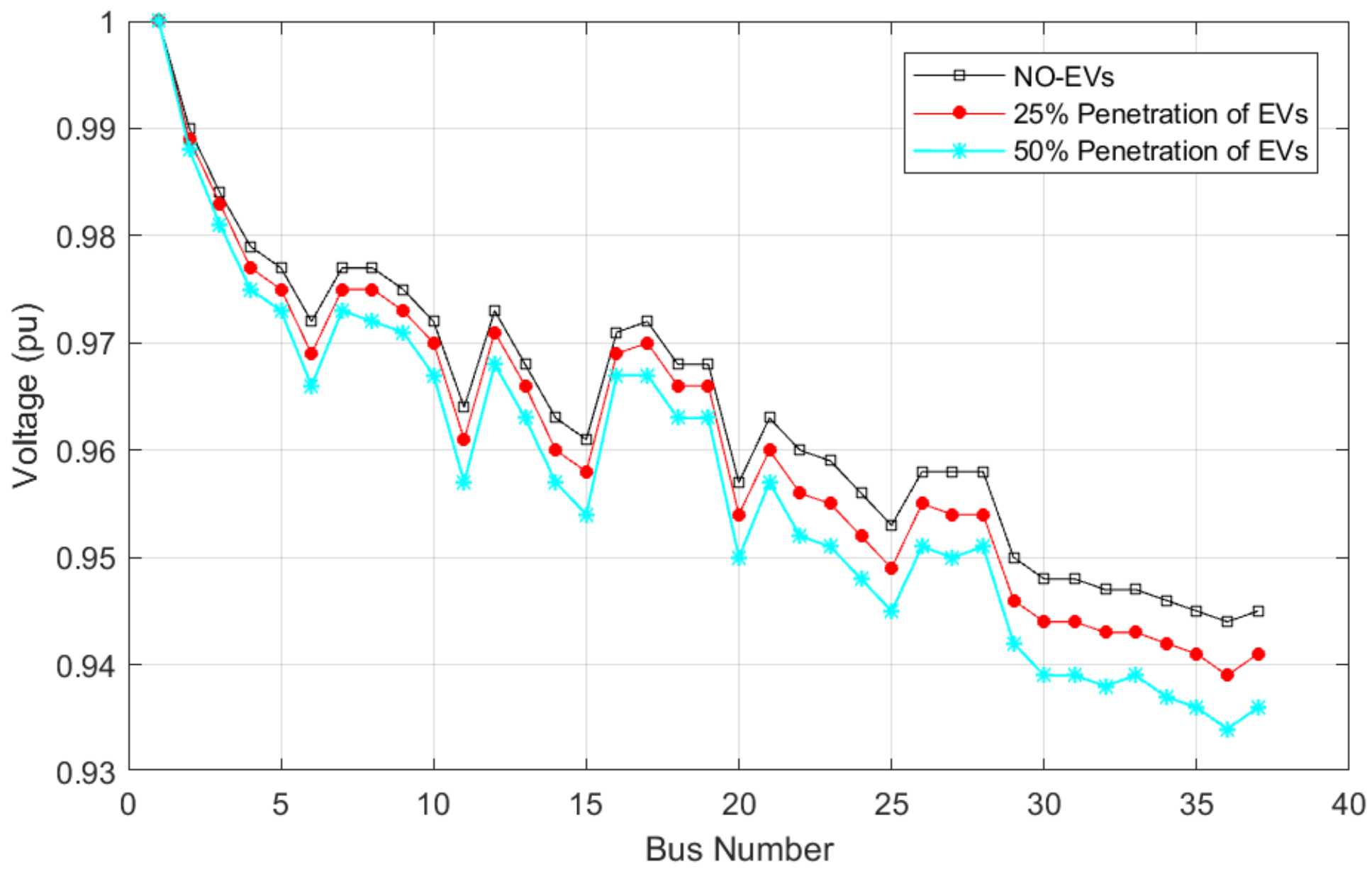

Figure 7

Voltage range of different network buses at different diffusion coefficients of EVs 


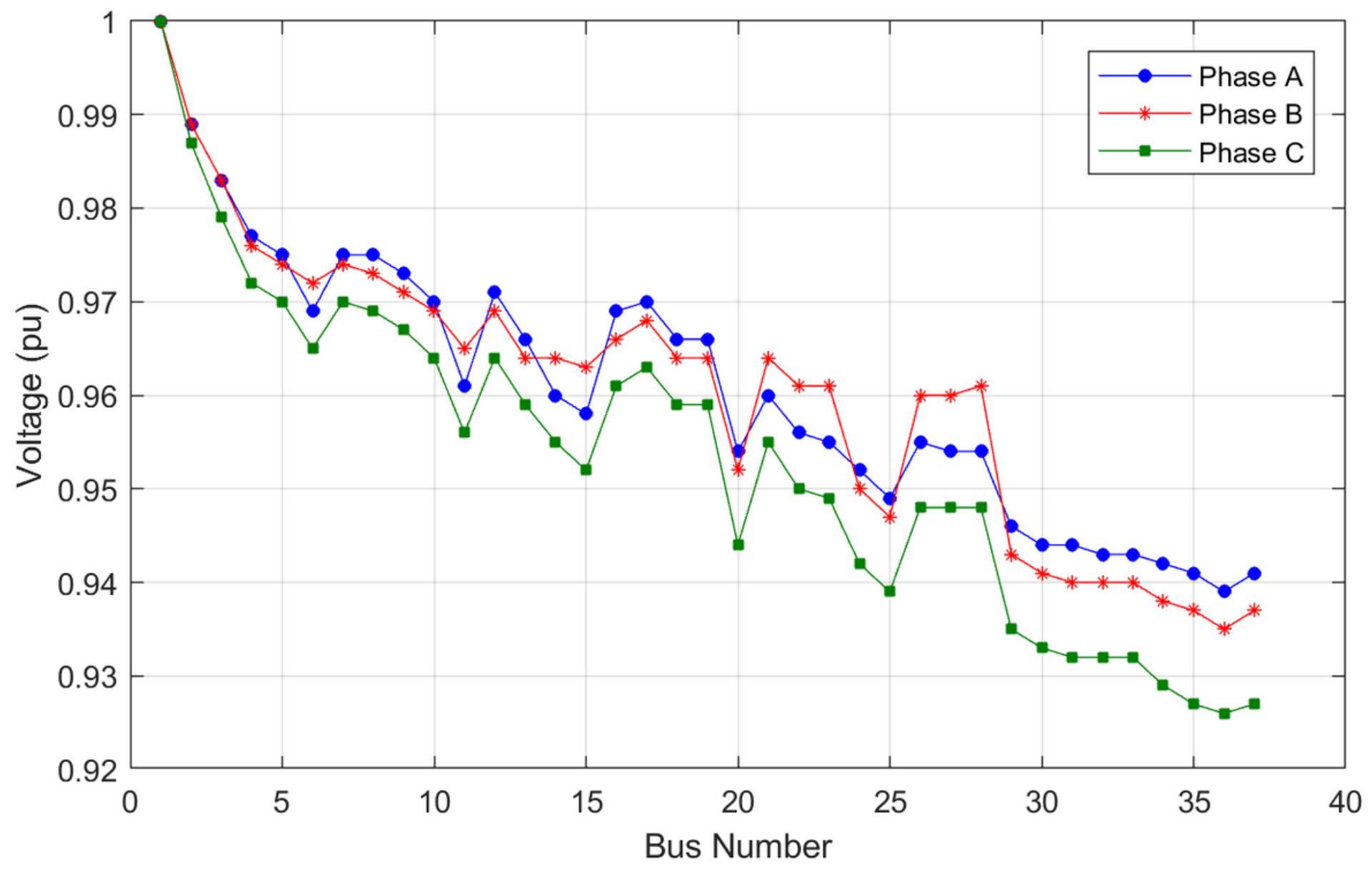

Figure 8

Voltage of different phases in each bus 


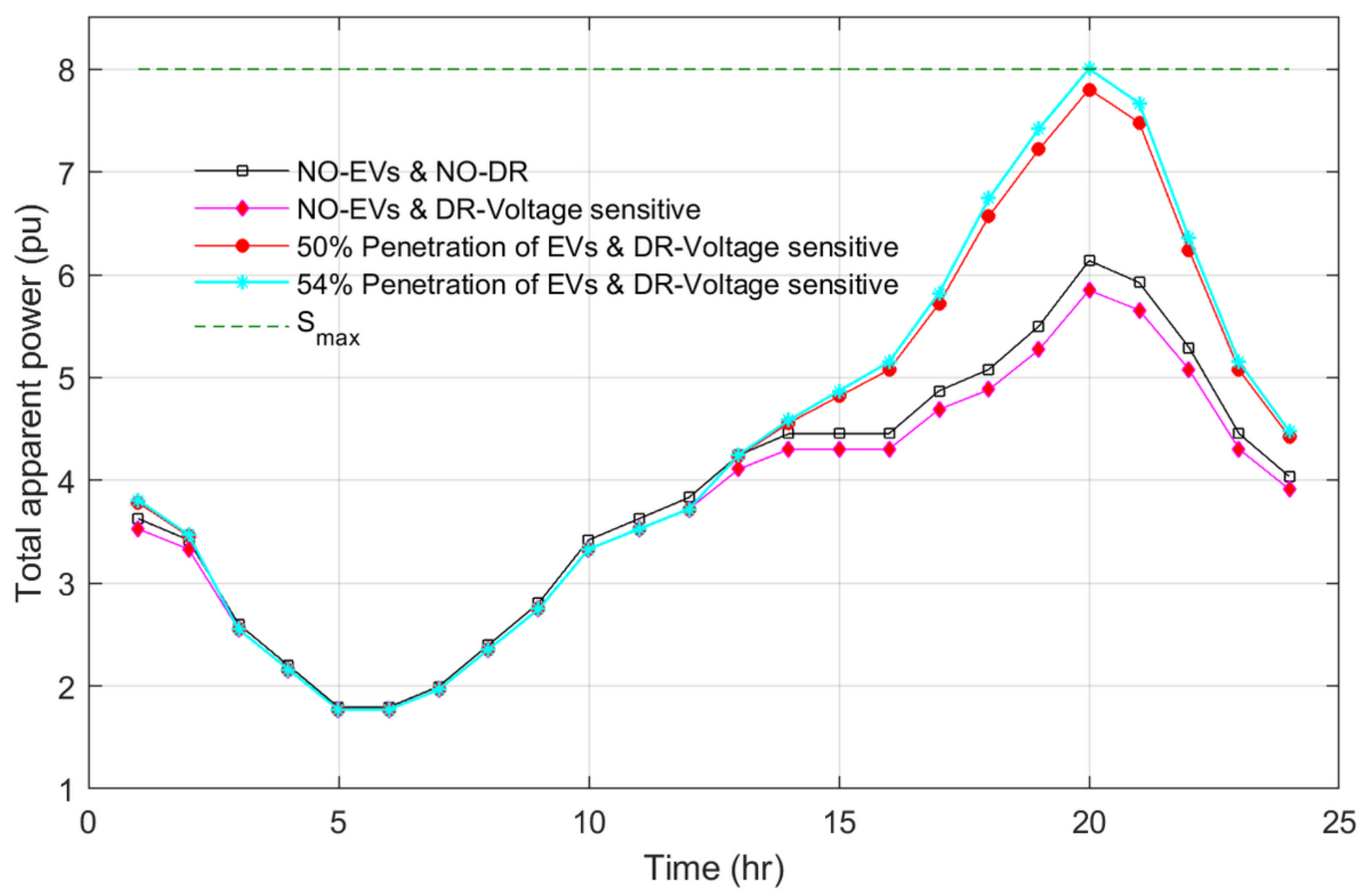

Figure 9

Hourly demanded network power (load profile) in different EV diffusion coefficients 


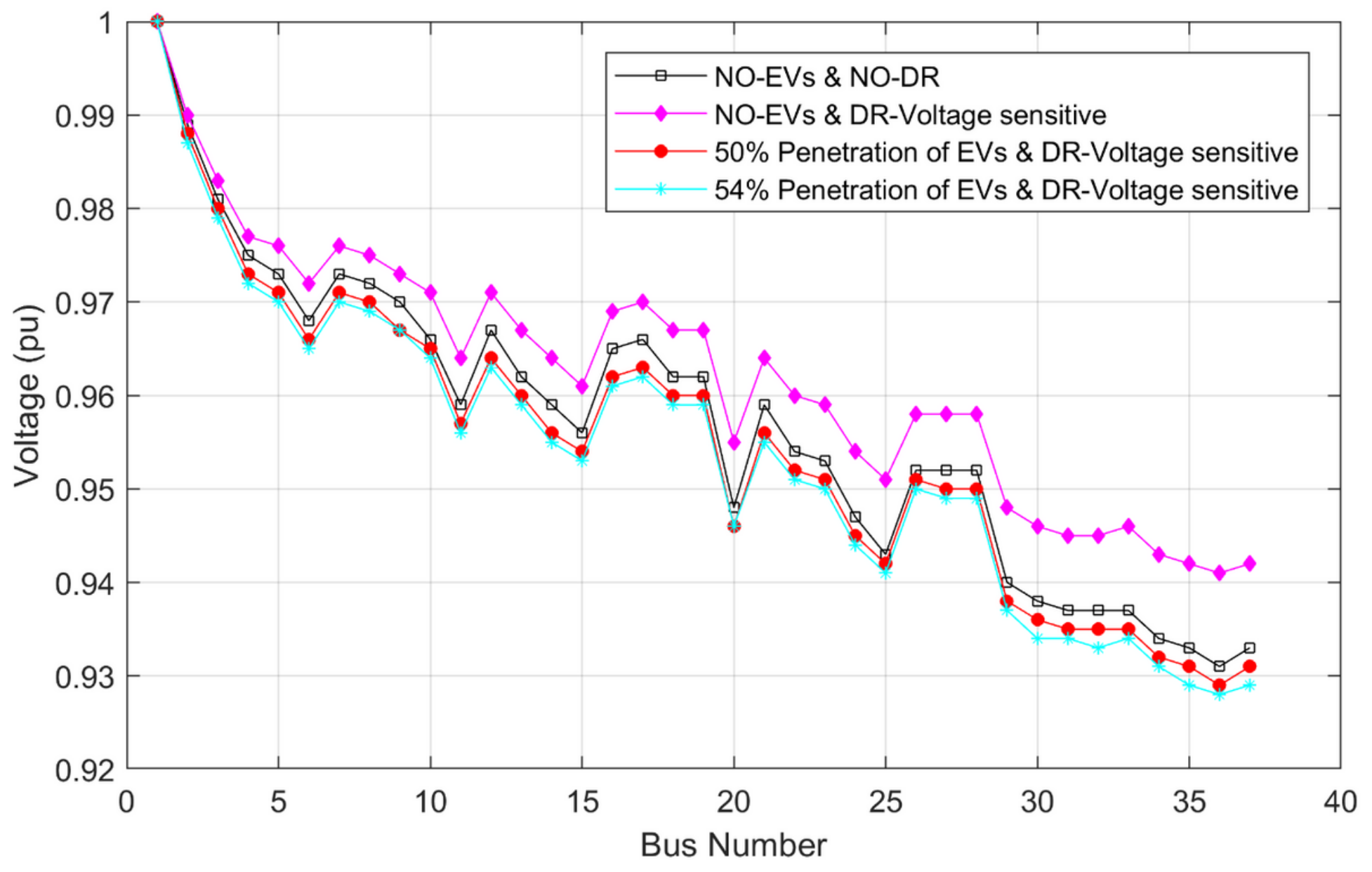

Figure 10

Voltage range of different network buses at different diffusion coefficients of EVs 


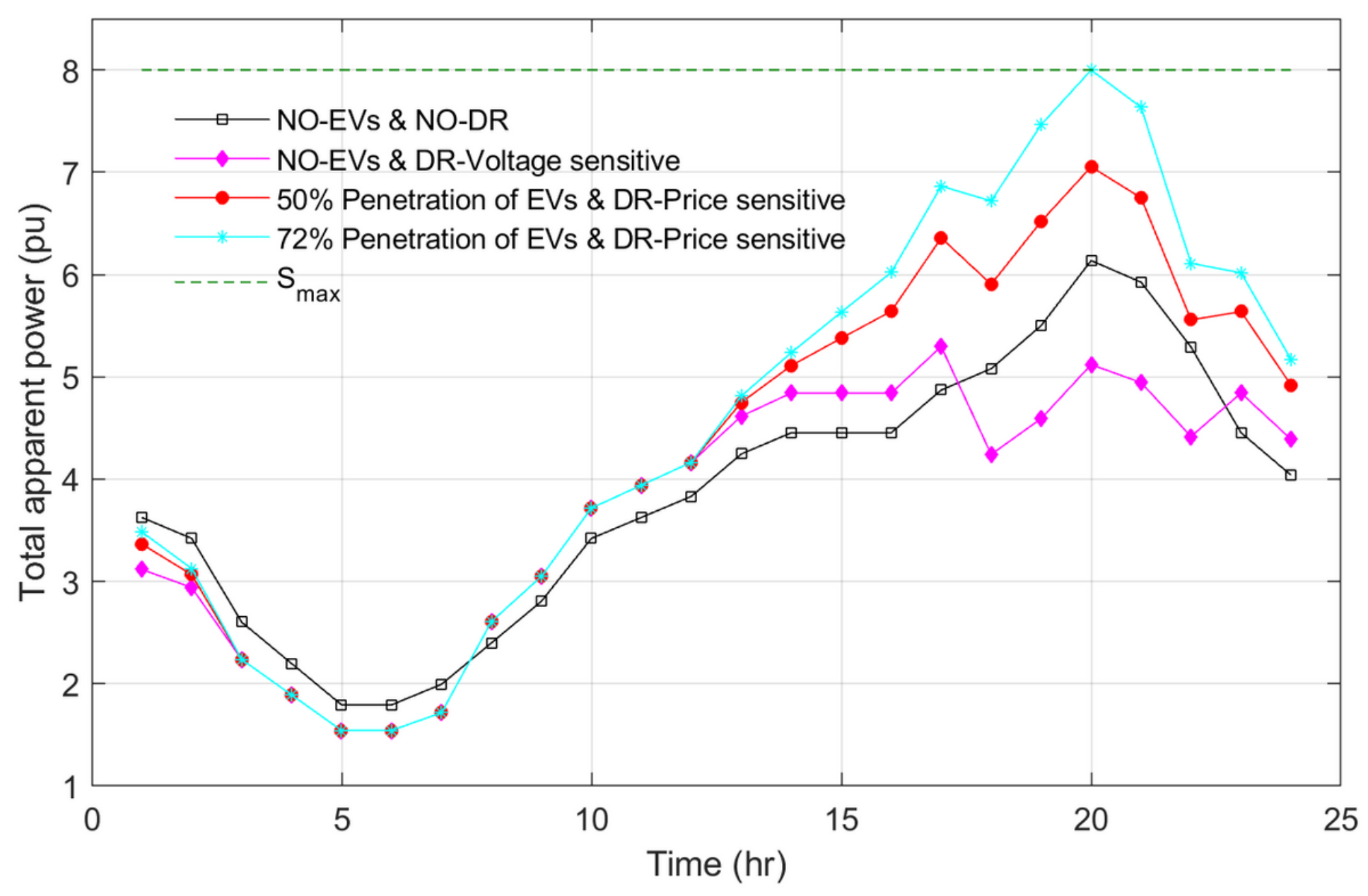

Figure 11

Hourly demanded network power (load profile) in different EV diffusion coefficients 


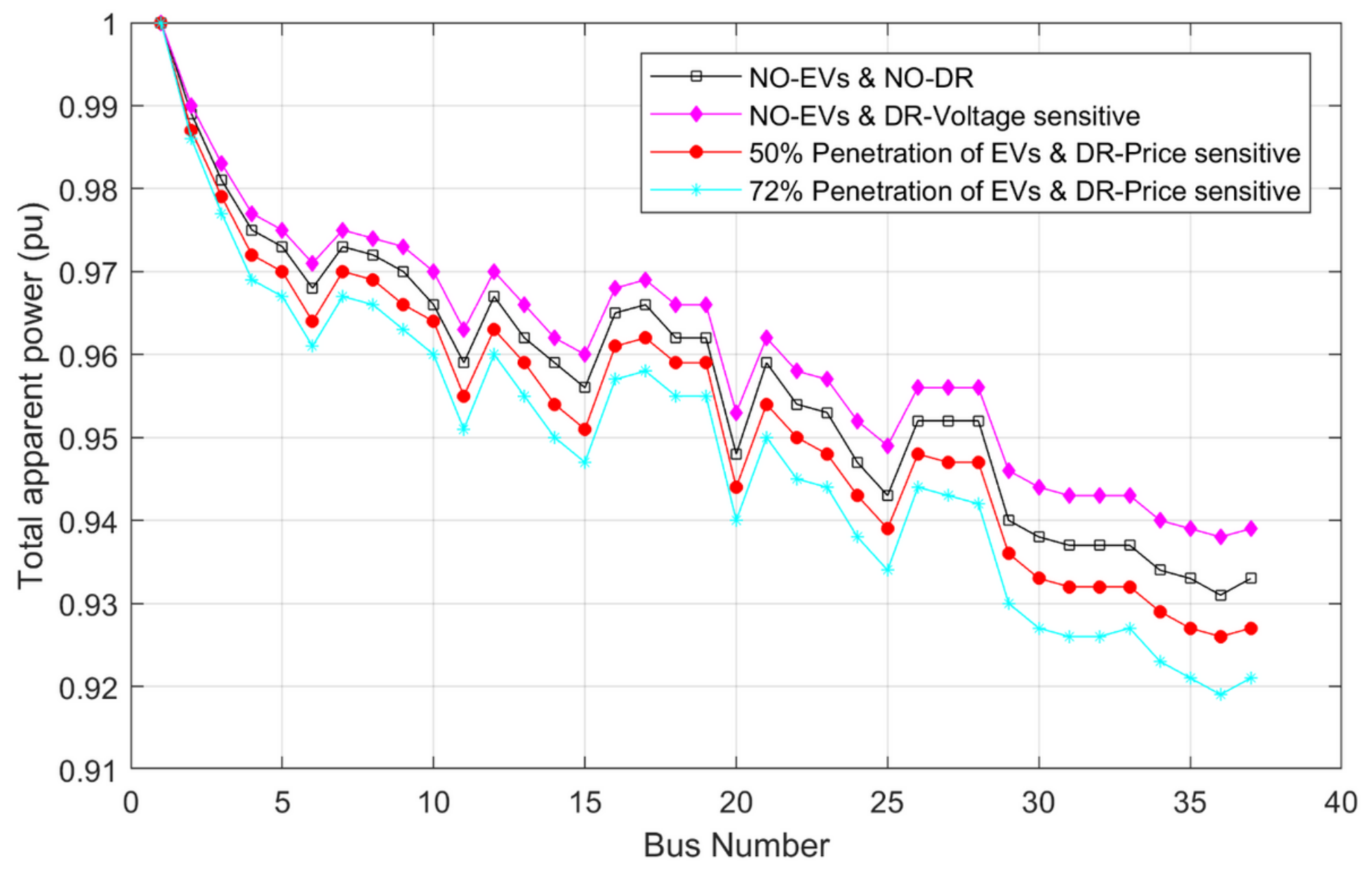

Figure 12

Voltage range of different network buses at different diffusion coefficients of EVs 


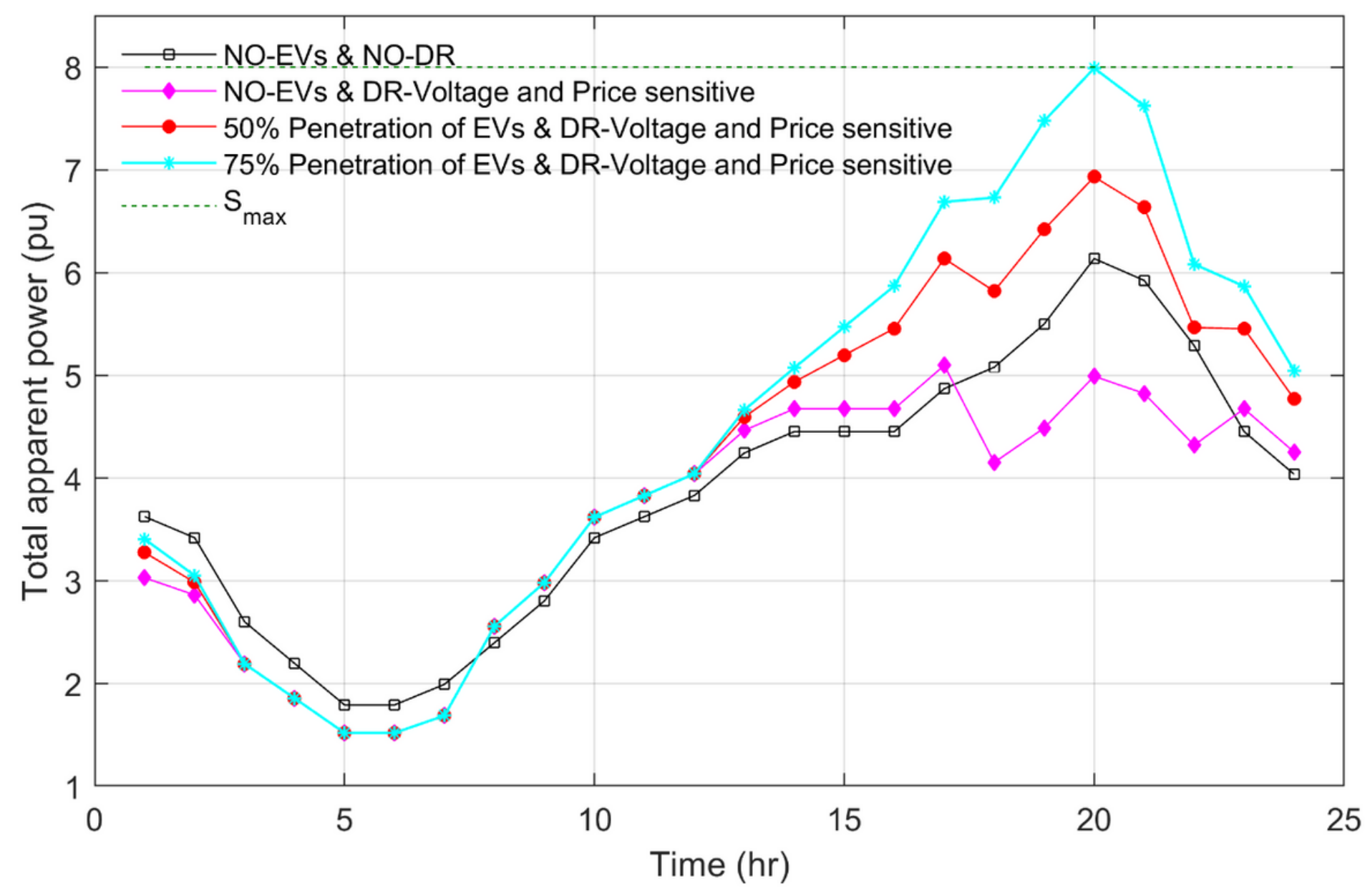

Figure 13

Hourly demanded network power (load profile) in different EV diffusion coefficients 


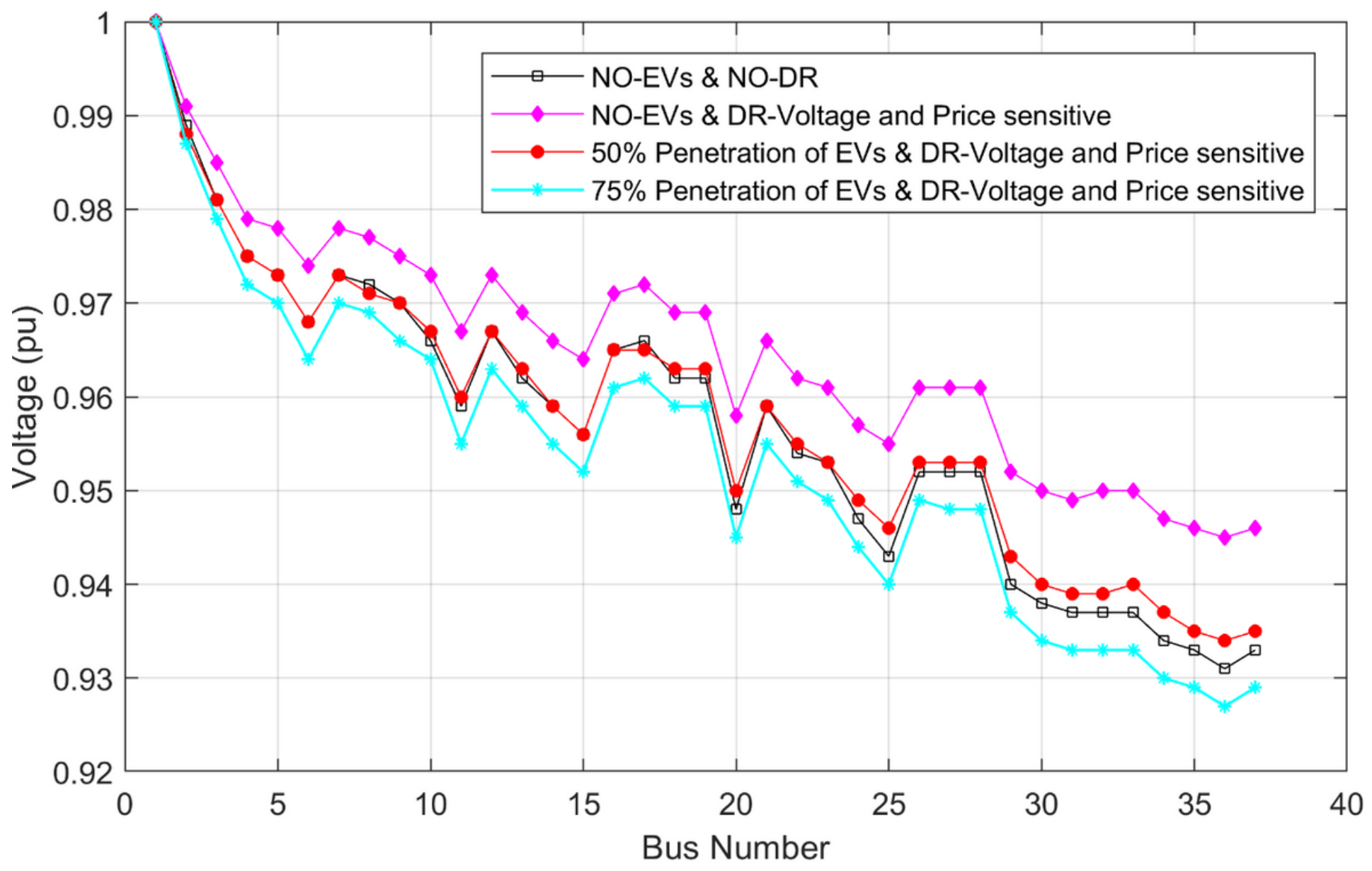

Figure 14

Voltage range of different network buses at different diffusion coefficients of EVs

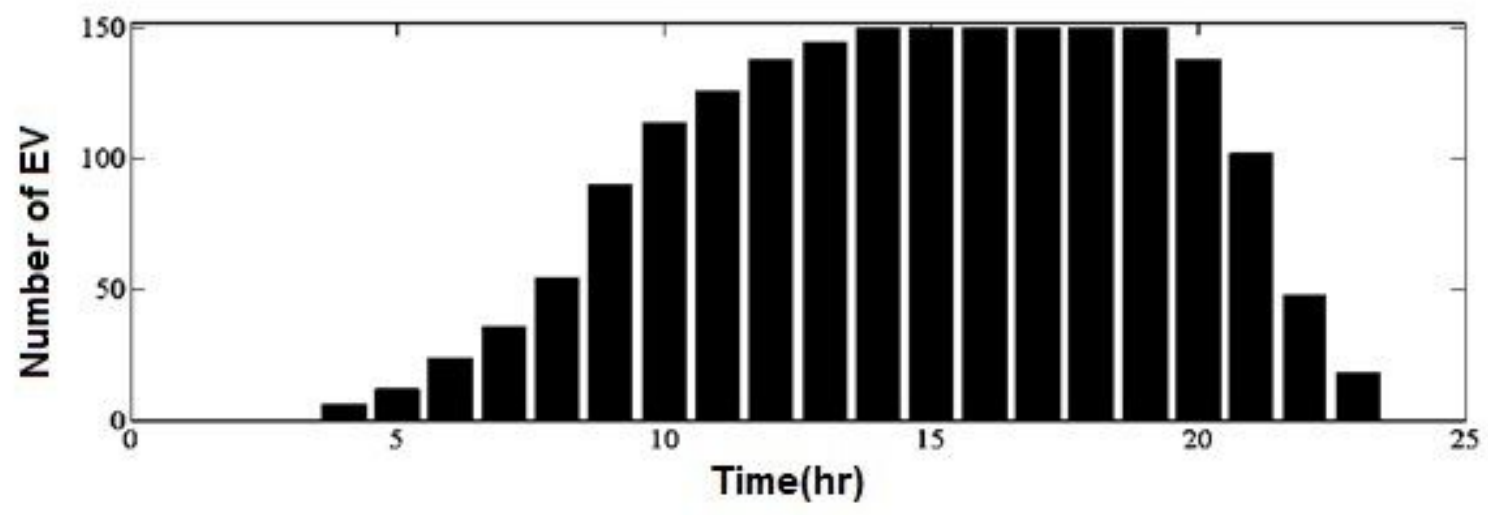

Figure 15

Number of vehicles connected to the network at different times based on maximum penetration coefficient 


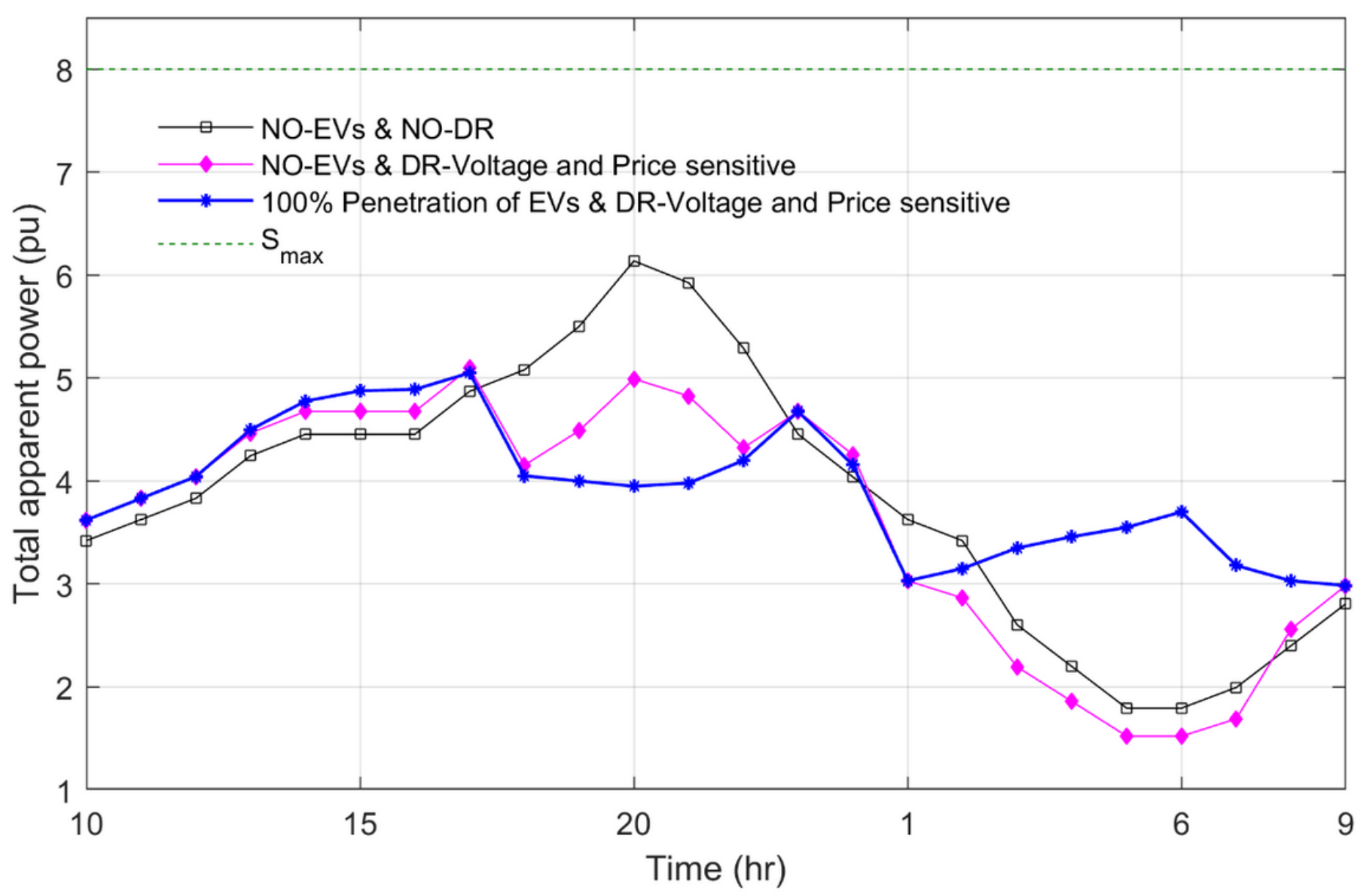

Figure 16

Hourly demanded network power (load profile) per hour at 100\% EV infiltration rate 


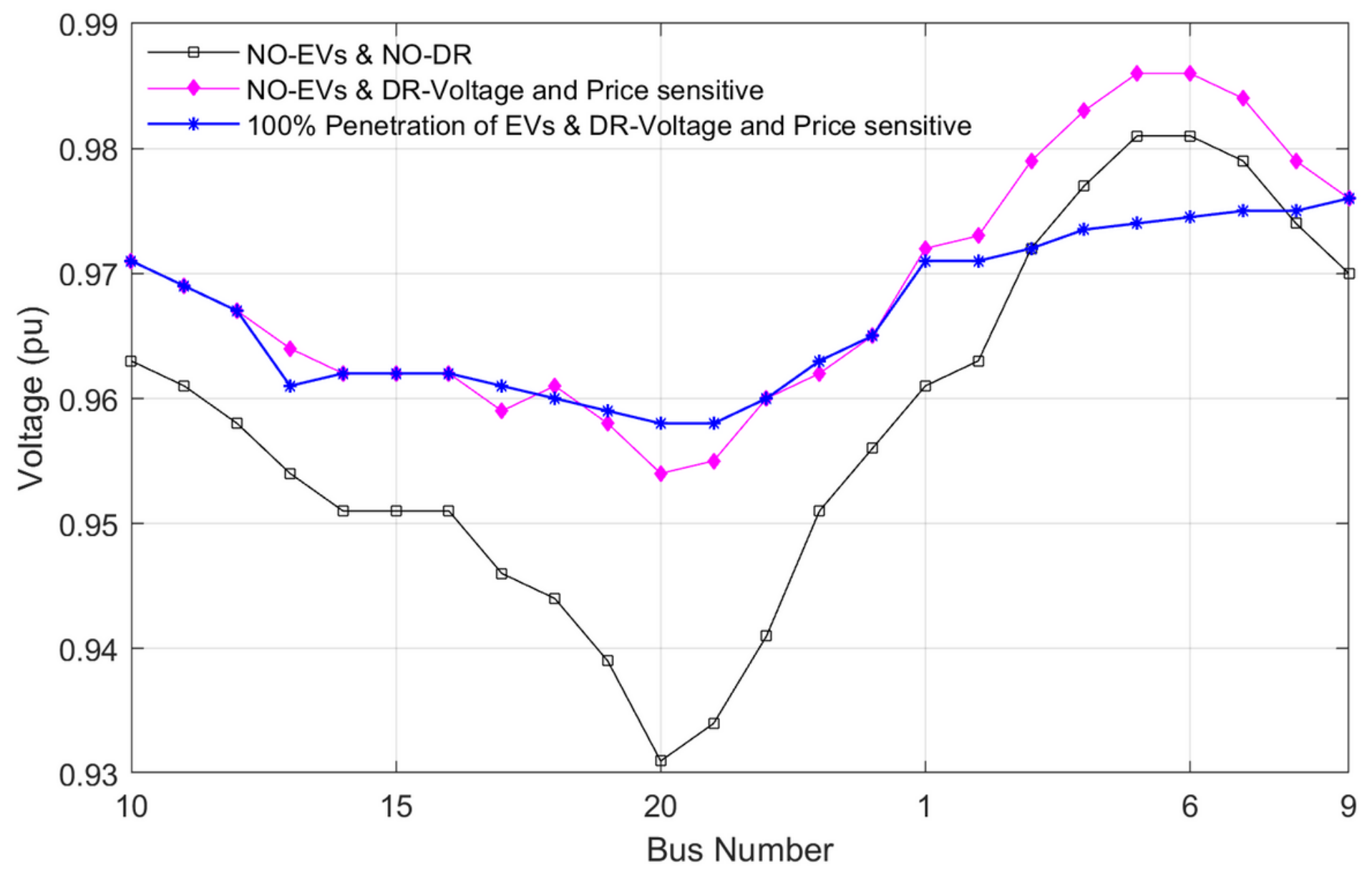

Figure 17

Voltage range of different network buses in different diffusion coefficients of Evs 